\title{
Sobre a ideia de uma Teologia da Cultura de Consumo: ensaio de um olhar tillichiano sobre a cultura de consumo.
}

\author{
Victor Siqueira Santos ${ }^{1}$
}

\section{RESUMO}

Este ensaio visa apontar um caminho para a construção de uma teologia da cultura de consumo a partir da teologia da cultura de Paul Tillich. Para tal, o primeiro objetivo será entender, pelo viés antropológico, o que é e quais são as principais características da chamada cultura de consumo. Após, então, é pretendido mostrar a teologia da cultura de Paul Tillich como uma que visa superar a separação entre cultura e religião defendendo que toda e qualquer criação cultural é capaz de trazer consigo um conteúdo religioso. Portanto, é tarefa da teologia da cultura analisar tais manifestações culturais sempre do ponto de vista de seu conteúdo substancial (Gehalt). Como delimitação necessária, será considerado como fundamento teórico o texto Über die Idee einer Theologie der Kultur (Sobre a ideia de uma teologia da cultura), proferido por Tillich em 16 de abril de 1919 à Sociedade Kantiana de Berlim, visto que esta conferência é a primeira aparição pública de sua teologia da cultura. A hipótese consiste, por fim, em mostrar que, a partir da teologia tillichiana, é possível afirmar a cultura de consumo como uma esfera cultural que absolutiza o caráter autônomo da cultura, travestindo-a de teonomia.

Palavras-chave: Cultura de consumo; Teologia da cultura; Paul Tillich;

\section{ABOUT THE IDEA OF A CONSUMER CULTURE THEOLOGY: ESSAY OF A TILLICHIAN LOOK AT CONSUMER CULTURE}

\footnotetext{
ABSTRACT

The paper proposes a construction for what it is called a "consumer Theology of Culture", according to Paul Tillich's Theology of Culture.

1 Mestre (2017) e Doutorando em teologia sistemático-pastoral no PPG em teologia da Pontifícia Universidade do Rio de Janeiro, PUC-Rio. E-mail: sem.victorsantos@gmail. com. Lattes: http://lattes.cnpq.br/7051636480812647.
} 
First, through an anthropological perspective, the understanding of what is and what are the main features of a consumer culture. After that, the paper presents Tillich's Theology of Culture as a overcoming-gap theology between culture and religion on the argument that all cultural movements are able to bring with themselves a religious content. The Theology of Culture's task analyzes cultural manifestations from the point of view of its substantial content (Gehalt). Because of a necessary delimitation, the text Über die Idee einer Theologie der Kultur (About the idea of a Theology of Culture), uttered by Tillich to the Berlin Kant Society in April $16^{\text {th }} 1919$, will be considered as the theoretical ground of Thillich's Theology of Culture, since this conference was the first public explanation about it. Finally, the hypothesis consists in showing that, from Tillich's Theology of Culture, it is possible to affirm the consumer culture as a cultural sphere that turns into absolute the autonomous character of the culture by faking it as theonomy.

Keywords: Consumer culture; Theology of culture; Paul Tillich;

\section{Introdução}

O termo "cultura de consumo" surge já na modernidade tardia, ou pós-modernidade, e não possui grande carga histórica de pesquisas se comparado a outros temas modernos e pós-modernos. Por isso, para que entendamos tal objeto de estudo é necessário, primeiro, recorrer a tempos anteriores ao próprio termo, buscando mudanças históricas da relação entre "cultura e consumo" que foram importantes para a configuração da "cultura de consumo" como esta é entendida hoje. Levaremos em consideração, aqui, a Inglaterra dos séculos XVI e XVIII e a França do século XIX, devido a importantes elementos da relação "cultura e consumo" surgidos nelas e que também estão presentes na cultura de consumo atual. A partir do apontamento dessa relação e suas evoluções será possível, então, observar como mudanças filosóficas, sociais e econômicas contribuíram para a construção da cultura de consumo no fim do século XIX e ao longo do século XX, como também se moldaram a partir dela. Esta dinâmica ganha contornos cada vez mais complexos ao longo do século passado, gerando, então, interesse de estudiosos que, ao longo do tempo, se propuseram a analisar e teorizar os vários aspectos desse sempre novo e renovável quadro cultural. 
Quanto à teologia da cultura do teólogo e filósofo Paul Tillich, teremos como objetivo primeiro pensar um dos significados modernos da palavra "cultura", focando em como este desafia a reflexão teológica por ter como pressuposto o avanço de uma modernidade cada vez mais autônoma. A partir deste desafio, algumas construções teológicas foram feitas. O segundo objetivo, então, será apresentar a teologia da cultura de Tillich como uma destas construções. A partir dela, o autor defende que, desde que a igreja protestante aceitou a existência de uma cultura secular, não há separação entre cultura e religião, e, portanto, a cultura deve ser objeto do estudo teológico. A teologia da cultura tem como tarefa primeira sempre observar os acontecimentos históricos e, portanto, culturais, para, sobre eles, lançar um olhar teológico. Partindo deste ímpeto, Tillich construirá esta teologia, que nasce e evolui ao longo de sua vida acadêmica. É considerado o "nascimento" da teologia da cultura tillichiana o dia 16 de abril de 1919, no qual ele proferiu a palestra "Über die Idee einer Theologie der Kultur" (Sobre a Ideia de uma Teologia da Cultura) para a Sociedade Kantiana de Berlim. Neste texto, é apresentado publicamente, pela primeira vez, o fundamento teórico de sua teologia da cultura. Apresentar tal fundamento teórico é o terceiro objetivo deste tópico.

Por fim, serão apontados, partindo da teologia da cultura tillichiana, alguns caminhos possíveis para a construção de uma teologia da cultura de consumo. Mesmo com a ciência de que Tillich nunca foi crítico direto de uma "cultura de consumo", serão levadas em consideração as críticas que o teólogo fez ao liberalismo econômico, ao capitalismo, à sociedade industrial, à sociedade técnica e à desumanização, que são realidades já presentes em seu tempo e que estão totalmente ligadas às construções da cultura de consumo.

\section{Cultura de consumo}

\subsection{Cultura e consumo}

O significado atual da palavra "consumo" só é entendido através de um contexto histórico nascido no século XIX e que é consolidado ao longo do século XX. Antes do século XIX, a palavra "consumo" era carregada de um significado negativo, na maioria das vezes em que 
empregada. Na língua inglesa, segundo o antropólogo inglês Raymond Williams, o verbo consumir existe desde o século XIV com significado semelhante a "destruir"; "esgotar", "gastar". (WILLIAMS apud FONTENELLE, 2017, p. 17). Isto nos lembra de uma das traduções de um escrito bíblico que se refere a Deus como um "fogo consumidor". $\mathrm{Ou}$ seja, um fogo que destrói, que põe fim, que esgota. O entendimento moderno do "consumo" é desenvolvido somente nos EUA, no século XX. E este entendimento já não é mais negativo, mas, sim, positivo, pois vem na esteira da criação de uma mentalidade econômica e social baseada na produção industrial capitalista, na qual os objetos se tornam bens a serem consumidos e as pessoas se tornam suas consumidoras. E quando se diz "criação de uma mentalidade econômica e social" é porque, de fato, o ser humano como consumidor, da forma como o concebemos atualmente, não é fruto de um processo histórico natural que simplesmente aconteceu, mas é resultado de um caminho criado sobre deliberações. A relação que temos com o consumo hoje é, em grande parte, fruto de direcionamentos históricos que agiram, sobretudo, nos âmbitos econômico e social. E, a partir destes, alcançaram outras dimensões da cultura humana, causando grande impacto sobre elas e transformando totalmente a concepção do ser humano sobre si mesmo e sobre tudo com o que ele interage, criando assim um sistema cultural.

Isto quer dizer que há um recorte histórico, geográfico, político, econômico e social a partir do qual abordaremos o que chamamos de cultura de consumo. Ela é a cultura desenvolvida pela mentalidade capitalista no século XIX e que, ao longo do século XX, se espalha por todo Ocidente, atingindo escala global.

Contudo, para entender a cultura de consumo atual, é necessário mencionar algumas relações entre cultura e consumo que contribuíram para sua gênese. Há estudos antropológicos que trazem a relação entre cultura e consumo em sociedades anteriores ao período histórico aqui apontado como o início do capitalismo. O antropólogo Grant McCracken, em seu livro "Cultura e consumo" (McCRACKEN, 2003), aponta que mesmo antes do século XIX, houve mudanças paradigmáticas em relação ao consumo já na Inglaterra elizabetana, no século XVI, e que

2 "Porque o nosso Deus é fogo consumidor", Hebreus 12. 29 em: BÍBLIA do pregador. Barueri: Sociedade Bíblica do Brasil; Curitiba: Editora Evangélica Esperança, 2009, p. 1264. 
estas mudanças se consolidaram na Inglaterra do século XVIII, tendo paralelos também paralelos e aprofundamentos importantes na França do século XIX.

Seguindo os estudos do historiador inglês Neil McKendrick (McKENDRICK; BREWER; PLUMB, 1982), McCracken escreve que, no século XVI, a rainha Elizabeth I dava enormes banquetes aos nobres que vinham de diversas partes da Inglaterra, ocasiões nas quais não somente esbanjava comidas e bebidas fartas, mas também exibia seu vestuário exagerado. E isso não fazia parte apenas de uma reunião social, mas também de uma demarcação social simbólica na qual a rainha mostrava sua superioridade diante dos nobres de seu reino. E, através da inteligência estratégica que lhe era característica, a rainha buscava fazer valer a pena os gastos de tais ocasiões. Ao passo que ela atraia os nobres para perto da corte, ela também se tornava sua fonte direta de distribuição da riqueza real que lhes era dada, centralizando em si mesma o poder e retirando a necessidade de intermediários. Isto significava o uso simbólico e político do consumo para aumentar o controle sobre a nobreza bem como a dependência desta para com a corte. Se os nobres desejassem algum favor real, deveriam sair de suas localidades para irem conquistar, pessoalmente, a simpatia da rainha, em Londres. Desta forma, "o simbolismo supercarregado da corte monárquica, da hospitalidade e do vestuário converteu-se na oportunidade para a persuasão e a instrução políticas" (McCRACKEN, 2003, p. 31).

A busca pela atenção da corte criou uma acirrada concorrência entre os nobres, que agora brigavam entre si por posição social. Nesta disputa, viam seus gastos com viagens, roupas e acessórios aumentarem significativamente, criando um novo padrão de consumo. Os nobres, que dentro de sua localidade gozavam de prestígio social e tinham responsabilidades políticas e econômicas (tais como intermediar os recursos vindos da realeza), viam a distância e o senso de coletividade para com sua localidade se esvaírem. O nobre não era mais aquele que intercedia pela localidade, mas aquele que tinha suas escolhas pautadas pelo consumo individualista que a disputa social lhe exigia. Este novo padrão de consumo diferenciava o nobre de seus subordinados não apenas pela quantidade das coisas que consumia, mas pelo tipo de coisas que consumia. $\mathrm{O}$ gosto da nobreza inglesa deixou de ser a valo- 
rização dos bens duráveis que permaneceriam na família por gerações (imóveis, mobília, obras artísticas...), para ser a valorização do que é novo, daquilo que imediatamente expusesse seu poder de consumo.

Dois desdobramentos resultaram desta mudança no gosto dos superiores. O primeiro do que os gostos dos superiores e dos subordinados foram radicalmente diferenciados. Onde antes havia existido diferenças de grau entre o consumo de superiores e subordinados, agora havia diferenças de tipo. Os superiores e os subordinados desejavam agora coisas diferentes. Uma espécie de diferenciação de estilos de vida estava tomando lugar. Diferenças de posição social estavam se tornando diferenças de estilo, de preferência estética e de atitude. Os grupos dos superiores e dos subordinados estavam começando a construir e a viver em diferentes mundos de bens. (McCRACKEN, 2003, p. 34).

A mudança social na Inglaterra provocou importantes mudanças no modo de consumo. Passou-se da valorização do bem antigo para o novo e do senso familiar-coletivo ao individual, aumentando ainda mais o abismo entre as camadas sociais. Na relação entre nobres e subordinados, o gosto dos superiores tomou um contorno tal que fez com que eles atraíssem para si, ao mesmo tempo, o estranhamento e a atenção/ admiração dos subordinados. Tais mudanças sociais baseadas em um novo padrão de consumo e disputa trarão profundas consequências para os séculos subsequentes.

No século XVIII, McCracken diz haver uma segunda mudança paradigmática na relação cultura e consumo. Segundo ele, este foi um século no qual houve uma explosão do consumo. Ainda seguindo o desenvolvimento do historiador Neil McKendrick, o antropólogo escreve que “o século XVIII viu o 'nascimento' da sociedade de consumo e os primórdios de nossa própria cultura de consumo moderna." (McCRACKEN, 2003, p. 36). A individualização e a preferência pelo novo que já havia surgido com os nobres da Inglaterra elisabetana do século XVI, agora estão consolidadas. Os padrões de consumo que, no séc. XVI, eram tidos como extravagantes e luxuriosos, passaram a participar da sociedade como sinônimo de bom gosto. Os produtos que eram consumidos vez ou outra, agora estão disponíveis quase diariamente através de feiras, comércios e vendedores ambulantes. "Como resultado, as 'luxúrias' passaram a ser vistas como 'bons costumes', e os 'bons 
costumes' passaram a ser vistos como 'necessidades'. Mesmo as 'necessidades' sofreram uma dramática metamorfose em estilo, variedade e disponibilidade" (McCRACKEN, 2003, p. 37).

Outra mudança importante do século XVIII foi o olhar das classes subordinadas em relação aos novos padrões de consumo das classes superiores. De uma estranheza/admiração passou-se então à possibilidade e à vontade de também participarem desta nova onda de consumo. A prosperidade pela qual passava a Inglaterra permitiu que o acesso a essa nova forma de consumo também alcançasse as classes subordinadas.

A Europa hierárquica que sempre observava modas no vestuário começou na corte e foi se deslocando em direção à nobreza, à pequena nobreza, às classes médias e às classes baixas, conduzida inexoravelmente pelo duplo mecanismo de imitação dos subordinados e de diferenciação dos superiores. (McCRACKEN, 2003, p. 39).

O consumo e os aspectos culturais ligados a ele não se limitavam mais a um nicho social, mas agora circulavam entre as camadas sociais através do efeito que, no século XX, o marketing chamaria de trickle-down. Esse nome é dado ao movimento no qual as classes subordinadas tendem a copiar os desejos de consumo das classes superiores. Ou seja, partindo desse efeito, as classes superiores são consideradas a porta de entrada para o espalhamento de tendências e desejos por toda a sociedade, e, no século XVIII, os comerciantes já estavam cientes disto. As camadas superiores eram estimuladas a aderir às tendências da moda que, logo em seguida, eram desejadas e procuradas pelas camadas subordinadas. E isso era um problema para as classes superiores porque seu status era sustentado exatamente em diferenciar-se das subordinadas através de uma posse-consumo peculiar. Logo, após terem seus hábitos e objetos de consumo copiados, só restava então aderir às novas tendências da moda para que a distância para as classes subordinadas fosse mantida. Esse é um círculo de consumo que perdura até os dias de hoje.

Neste círculo não estão envolvidas somente pessoas e mercadorias, mas desejos, status, símbolos e imitações. Os objetos perdem seu caráter de simples utilidade e passam a carregar consigo significados múltiplos, tais como de pertença e individualização. A pessoa é aquilo 
que consome e consome aquilo que ela é. A produção de objetos de consumo passa a se basear nos desejos da sociedade de consumo ao passo que também passa a influenciá-los.

Este consumidor era objeto de tentativas cada vez mais e mais sofisticadas de incitar desejos e dirigir preferências, e estava começando a viver em um clima artificialmente estimulado, que retirava seus gostos e preferências do comando da convenção e da tradição local, transferindo-os de modo crescente para as mãos das emergentes forças do mercado. (McCRACKEN, 2003, p. 38).

Eis o início da relação intrínseca entre cultura e consumo que caracteriza a cultura de consumo moderna. Ou, como bem afirma McCracken: "O 'mundo dos bens' estava se constituindo firmemente como coextensivo ao mundo da vida social." (McCRACKEN, 2003, p. 43).

No século XIX, esta relação se aprofundou como nunca antes, a ponto de "cultura" e "consumo" não serem mais duas instâncias que se relacionam, mas formarem uma unidade. A vida social e os múltiplos significados em torno do consumo estavam em plena relação dialética, na qual uma era fator de transformação da outra. O mundo da compra e da venda influenciava a organização social e a visão que a sociedade e os indivíduos tinham de si mesmos, dos outros e do todo social. É o nascimento de uma "cultura de consumo". A partir dela, uma sociedade podia ser entendida através de diferentes e novos estilos de vida baseados no consumo. As sociedades europeias vão ganhando arranjos sociais estruturados através dos diferentes gostos e mentalidades.

McCraken, agora baseado no livro da historiadora estadunidense Rosalind Williams "Dream worlds: mass consumption in late nineteenth Centry France" (WILLIAMS, 1982), traça três estilos de consumo da França do século XIX que superaram o modelo aristocrático de consumo, que mesmo após a revolução francesa, ainda subsistia no estilo de vida da burguesia. O primeiro estilo de consumo abordado é o consumo de massa. Este estilo era baseado no uso da fantasia, do desejo e no incentivo ao esbanjamento, como uma evolução do estilo de vida aristocrático. $\mathrm{O}$ estilo de vida de massa ganhou materialidade nas lojas de departamentos (grands magasins) surgidas na França do século XIX, estas que foram grande laboratório para novas técnicas de 
marketing e de compra e venda. O segundo estilo de consumo era o estilo de vida da elite. $\mathrm{O}$ padrão de consumo da elite se baseava numa aristocracia dos gostos, na qual certos padrões estéticos eram postos como superiores ao estilo de consumo da massa. O gosto elitista se materializava em certos estilos artísticos e nas escolhas de vestuário.

Este era o modelo de consumo inspirado por Beau Brummel e pelos dândis que seguiam seu exemplo, tanto na Inglaterra quanto na França. Os dândis ridicularizavam os excessos do consumo burguês e aristocráticos e se declaravam como a nova elite, uma aristocracia que fazia jus a este nome pelo bom gosto, e não pela civilidade e pelas boas maneiras. (McCRACKEN, 2003, p. 44).

Por fim, o terceiro estilo de consumo da França do século XIX em destaque é o estilo democrático de consumo. As pessoas que o aderiram viram nas mudanças de consumo da época a possibilidade de um estilo de vida mais simples, que fosse acessível e que dignificasse todas as pessoas comuns. Esse estilo de vida, naturalmente se opunha tanto ao estilo de consumo de massa, quanto ao estilo de consumo elitista. Ao primeiro, por este tratar o consumo como consumação individualista de seus desejos e fantasias, e ao segundo, por este usar o consumo para construir uma nova aristocracia.

Os três estilos de consumo existentes na França do século XIX trazidos por McCracken são bons exemplos práticos para um entendimento de como o fator do consumo já era parte da dinâmica social. Se no século XVIII nascia uma cultura do consumo, no séc. XIX, esta cultura se aprofundou e se tornou fator proeminente no que concerne às mudanças políticas, econômicas e sociais ocorridas no ocidente.

Este apanhado histórico trouxe situações decorrentes de lugares específicos (Inglaterra e França), contudo são de suma importância para se entender o que ocorrerá com todo o Ocidente no fim do século XIX e ao longo de todo século XX. Este período é marcado pelo início do capitalismo, um modelo de organização social no qual se relacionam valores mercadológicos com ideologias políticas e valores sociais. Nesse sistema, o consumo, e tudo que é relativo a ele, tem lugar primordial. E, com o passar do tempo, essa primordialidade só aumenta. A expansão e evolução do capitalismo são proporcionais ao desenvolvimento da 
cultura do consumo. Ao longo do século XX, esta se torna necessária para a perfeita operação daquele. É justamente neste período de aprofundamento, desenvolvimentos, teorizações e estudos acerca da cultura de consumo que se concentrará a primeira parte do presente ensaio.

\section{Modernidade e cultura de consumo: $\mathrm{O}$ "eu" e o sonho}

Os apontamentos históricos trazidos por Grant McCracken, no que tange à evolução da relação cultura-consumo, nos ajudam a entender alguns caminhos percorridos até o século XIX, um momento histórico crucial para a cultura de consumo contemporânea. Entretanto, é necessário também lançar um olhar sobre as mudanças filosóficas, políticas e econômicas que faziam desse período um ponto-chave para o forjamento de uma forma específica de cultura de consumo. Segundo a psicóloga e socióloga Isleide Fontenelle, a cultura de consumo, como a entendemos hoje, decorreu de uma revolução das mentalidades, que, por sua vez, foi consequência de outras duas revoluções: A Revolução Industrial e Revolução Política. Ela diz:

Mas se for possível definir uma pré-história da cultura de consumo, certamente ela pode ser contada a partir de uma revolução das mentalidades, denominação que estou dando a algumas transformações econômicas, políticas e subjetivas oriundas, por sua vez, de duas revoluções fundamentais para que a cultura do consumo emergisse: uma revolução industrial e uma política - tomando-se a Revolução Francesa como "tipo ideal" -, pois foram essas que deram forma ao que passamos a denominar "era moderna" e, por consequência, de indivíduo moderno. (FONTENELLE, 2017, pp. 19-20).

Seguindo o historiador Eric Hobsbawm (HOBSBAWN, 2012.), Fontenelle diz já haver, no fim do século XVIII, uma ideologia baseada na crença de um progresso individualista, secularista, e racionalista. Contudo, esta ideologia não havia alcançado ainda certo poder e certa disseminação. "Foi apenas com a dupla revolução que elas se tornaram centrais na moldagem de um novo mundo comandado pelo triunfo da 'indústria capitalista' e da 'sociedade burguesa liberal'." (FONTENELLE, 2017, p. 20).

Economicamente falando, a Segunda Revolução Industrial, no fim do século XIX, foi a mais impactante. A partir da capacidade de 
produção de produtos em escala e da circulação deles no mercado, passou a ser possível a estruturação de uma sociedade cujo objetivo fosse consumir o que foi produzido. Este é o início do período de um consumo de massa. É neste mesmo período que se espalharam as chamadas lojas de departamentos ${ }^{3}$, que foram uma espécie de laboratório para experimentar as técnicas e mecanismos em torno do consumo de massa. A partir dos magazines, firmou-se a articulação entre a produção de produtos feitos a máquina (produzidos mais rápidos e em maior número que os feitos a mão) e o estoque da loja. Nessa articulação entre produção e estoque, os produtos do estoque tinham que circular o mais rápido possível para que o lucro compensasse o investimento feito na produção através das máquinas. A estratégia dos magazines era manter uma margem de lucro baixa para ganhar na quantidade de venda. Vender rápido e volumosamente era questão de sobrevivência econômica. E, por isso mesmo, também houve, nesse período, o crescimento de interesse em assuntos relacionados às técnicas de venda. É, lá, por exemplo, que nasce a técnica da justaposição inesperada e da associação do produto a uma imagem de status.

As lojas de departamento são um exemplo perfeito do uso de técnicas de estímulo ao consumo que até hoje são utilizadas: a justaposição inesperada, ou seja, o critério de colocar diferentes objetos juntos, um ao lado do outro, a fim de suspender o caráter de uso dos mesmos e gerar um estranhamento que levaria ao desejo de possuí-los; a decoração e o caráter de espetáculo das vitrines, nas quais um vestido feito a máquina era posto ao lado da foto de uma duquesa, sugerindo uma clara associação entre o uso do vestido e o status da nobreza que este promoveria. Enfim, técnicas que tinham por intenção fundamental revestir os objetos de significações para além de sua utilidade. (FONTENELLE, 2017, p. 23).

Este é o fundamento da relação sociedade-consumo até hoje: imergir os objetos de significações para além de sua utilidade a fim de que sejam desejados não somente pelo que podem fazer, mas, sobretudo, pelo que podem representar ou simbolizar. Parte estrutural da cultura de consumo está nas significações com as quais os bens de consumo são

Department Stores, em inglês. Grands Magasins, em francês. 
banhados, e esta parte sofrerá aprimoramentos conforme o forjamento da cultura de consumo se aprofunda.

A primeira loja de departamentos foi a "Bon Marché", que surgiu em Paris, fundada em 1852. Mas, logo, surgiram lojas também em Londres e Chicago. Em todos os três casos, a existência das lojas e seus modos de operação trouxeram mudanças urbanas para seus entornos. Calçamentos e transportes públicos sofreram modificações para que o acesso às lojas fosse facilitado e suas estratégias fossem bem sucedidas. Seguindo a obra do sociólogo estadunidense Richard Sennett "O declínio do homem público" (SENNETT, 1998), Fontenelle diz:

Sennett nos mostra, ainda, como outros fenômenos correlatos também tiveram de existir para que a estratégia das lojas de departamentos - que era ter uma multidão de compradores - funcionasse. Foi necessária uma revolução urbana e nos transportes para que, de fato, os compradores pudessem chegar às lojas. Daí a criação dos grands boulevards em Paris, entre as décadas de 1850 e 60, assim como a criação de sistemas de transportes em Paris e Londres por volta desse mesmo período. Em Chicago, mostra-nos o autor, também houve essa combinação entre transporte rápido e comércio varejista, especialmente após o grande incêndio de 1871. (FONTENELLE, 2017, p. 22).

Sem dúvidas, as lojas de departamento tiveram um papel paradigmático na cultura de consumo. Elas foram o lugar que conseguiu dar materialidade a algumas mudanças filosóficas que já estavam presentes na Europa. As noções de autonomia e individualidade, por exemplo, estavam em grande crescente através da corrente de pensamento iluminista. Esta nova noção do "eu" em conjunto com as transformações sociopolíticas levou a uma grande mudança na percepção do indivíduo sobre seu lugar e sua imagem na sociedade. No Antigo Regime, o modo com que as pessoas se vestiam era determinado pela classe a qual pertencia, sendo elas proibidas, através de leis suntuárias, de se vestirem de acordo com posições sociais superiores às suas. Já no Novo Regime do capitalismo burguês, a classe trabalhadora era desejosa de e incentivada a - aderir aos costumes da burguesia, pois havia, agora, uma possibilidade de "mobilidade social" através do consumo. Por isso, então, a estratégia de venda de pôr a foto de uma duquesa ao lado de um vestido feito à máquina. $\mathrm{O}$ consumo não era mais pura e somente 
consequência da posição social, mas a possibilidade do indivíduo, autônomo e livre, expressar seus desejos e personalidades, como também de desempenhar novos papéis sociais. (FONTENELLE, 2017, pp. 2425) Essa mudança histórica, que segundo Fontenelle se deu a partir da Revolução Francesa, criou uma nova mentalidade. Agora, as pessoas não se veem mais resumidas ao grupo social ao qual pertencem, mas são tomadas pela noção de que existe um "eu", e que as possibilidades de ser desse "eu" são múltiplas.

Em outras, palavras, é a partir desse momento histórico que começa a se desenvolver a ideia de que haveria um 'verdadeiro eu' e que esse poderia (mas não necessariamente) se expressar em público por meio de um modo específico de se vestir, por exemplo. Era possível 'brincar com as aparências', 'ser outro'. O uso dos objetos na construção desse 'eu' que queria 'ser' ou 'parecer' passou a englobar muitos aspectos da vida cotidiana. É aqui que a revolução industrial e a revolução política convergem para uma transformação nas mentalidades da qual a cultura de consumo é tributária. (FONTENELLE, 2017, pp. 25-26).

Nas lojas de departamentos, toda essa nova dinâmica estava condensada. O individualismo do "eu" se encontrava com as múltiplas possibilidades de "ser outro", numa experiência na qual estavam igualmente envolvidas "consciência" e imaginação", "racionalismo" e "magia". Em seu livro "O paraíso do consumo: Émile Zola, a magia e os grandes magazines" (ROCHA; FRID; CORBO, 2016), os professores Everardo Rocha, William Corbo e a professora Marina Frid se baseiam no romance "O paraíso das damas" (ZOLA, 2008) do escritor francês Émile Zola, para fazer uma análise dos impactos antropológicos e culturais das lojas de departamentos e apontar sua contribuição para a estruturação do consumo moderno. E sobre isso, é afirmado:

Portanto, o modelo de negócios dos grandes magazines, que surge em meados do século XIX, está em linha com processos em curso no plano da cultura que impactaram valores, hábitos, gostos e o cotidiano urbano. (...) Vamos examinar como os grandes magazines consolidaram parâmetros de cultura e sociabilidade em um modelo de comércio que associa as práticas de consumo ao pensamento mágico, ao sagrado e à ritualização. Consolidaram, enfim, o consumo como o conhecemos hoje. (ROCHA; FRID; CORBO, 2016, pp. 12, 29). 
Ao mencionarem o caráter "mágico" das práticas de consumo, os autores tocam num ponto que foi e ainda é de suma importância para a cultura de consumo, a saber, o uso da imaginação, do sonho, da magia. Afinal, não basta ter a possibilidade de adquirir um produto de uma classe superior, há de se participar também de seu universo, entrar em seu estilo de vida, "brincar" no seu "faz de conta". As lojas de departamento souberam aproveitar muito bem este viés imaginativo para, através dele, atrair o consumidor. Voltando ao exemplo da foto da duquesa, é possível perceber que, nela há, além da sensação de uma "ascensão social", uma invocação imaginativa que convida a consumidora a brincar, sonhar, "fingir" que é a própria duquesa. Isso tem levado alguns estudiosos a levarem em consideração o papel do Romantismo na estruturação da cultura de consumo. Pois este foi, sobretudo, um movimento de valorização da fantasia, da imaginação e do desejo. $\mathrm{Na}$ obra "A ética romântica e o espírito do capitalismo moderno" (CAMPBELL, 2001), o sociólogo da religião inglês Colin Campbell busca trazer esta relação entre o espírito romântico e o crescimento na procura dos bens da era capitalista.

Colin Campbell relaciona a disseminação do ideário do Romantismo à crescente demanda por novidades e ao aumento dos gastos, especialmente com vestuários e divertimentos. Sugere que uma forma de hedonismo imaginativo está associada à incorporação de valores e hábitos - culto ao amor romântico, literatura de ficção e atividades de lazer - e, consequentemente, aos novos patamares de dispêndio na sociedade urbana inglesa em meados do século XVIII. (ROCHA; FRID; CORBO, 2016, p. 12).

O Romantismo surge no século XVIII como um movimento espiritual contrário à rigidez da racionalidade iluminista. A ênfase romântica estava nos sentimentos e na imaginação, e esses são exatamente os pontos explorados pela cultura de consumo. A antropóloga Diana Lima, escrevendo sobre o livro de Campbell diz: "ao lado da racionalidade, os valores românticos estão presentes no mundo moderno desde o século XVIII e são responsáveis pelo nascimento do que ele (Campbell) chama de espírito do consumismo, sem o qual o capitalismo não teria podido se consolidar." (LIMA, 2010, p. 33) Esses valores românticos baseados nas emoções e na imaginação, ajudam a retirar o tom de imoralidade 
que havia na sensação de prazer - tão comum da moral iluminista, construindo um novo estatuto moral do prazer. Esta abertura social e moral ao prazer abrem as portas para que o novo impulso consumista da burguesia fosse não somente aceito como também imitado, colocando tal impulso em outro patamar. O prazer não está mais somente nas mesas fartas e nos riscos das atividades de aventura, mas transferiu-se também para o universo da imaginação.

Com as transformações culturais propiciadas pelo Romantismo, relativas ao estatuto moral do prazer e à valorização da sensibilidade, o indivíduo moderno aprende a retirar prazer da atividade das emoções e da imaginação. Com a aceitação moral cada vez mais ampla do prazer e, ao mesmo tempo, o aprofundamento do uso da imaginação, por meio da leitura de romances, por exemplo, o indivíduo moderno tem abertas as condições que lhe permitem superar os limites dos sentidos estimuláveis. A imaginação vai além dos contratempos que a experiência física pode impor. Seu prazer não depende mais apenas da experiência, restrita e, às vezes, imperfeita. $\mathrm{O}$ indivíduo moderno aprende a fantasiar e a obter prazer com a imaginação. (LIMA, 2010, p. 36).

Não é à toa que o meio de expressão preferencial do romantismo era a arte (poemas, romances, peças de teatro), pois ela chega a dimensões de profundidade que a linguagem literal não alcança. Para isso, é muito comum a arte fazer uso dos símbolos, que sempre transpassam sua forma primária para apontar para algo para além deles mesmos. Este foi outro aspecto instrumentalizado pela cultura de consumo moderna e usado ainda nos dias de hoje. Para Campbell, essa dimensão simbólica e imaginativa é parte fundamental para o crescimento do espírito consumista, pois é ela quem rege a publicidade, que faz uso das imagens e dos símbolos para o estímulo de tais desejos e para a condução da imaginação do consumidor a um fim planejado.

Vale ressaltar que o trabalho de Campbell é, através de uma perspectiva fincada na realidade atual, observar os caminhos abertos pelo Romantismo e que foram trilhados pela cultura de consumo posteriormente, e não ao contrário, ou seja, tentar enxergar a presença de uma cultura de consumo no Romantismo. Como bem conclui Lima:

É preciso deixar claro que o autor não acredita que a intenção do Romantismo era de promover um crescimento de demanda por produtos e 
serviços em favor do aquecimento das forças comerciais capitalistas. Impulsionado inicialmente pela sua insatisfação com o diagnóstico corrente sobre a Modernidade, Campbell segue pegadas do movimento romântico depois de encontrar suas marcas na publicidade, e desvenda sua influência no mundo moderno. Ao enfatizar a sensibilidade e a expressão das emoções, o Romantismo propiciou o surgimento do consumidor moderno e abriu terreno para esse aspecto crucial no consumismo: a fantasia. (LIMA, 2010, p. 40).

Como é possível perceber, a cultura de consumo contemporânea é forjada em meio a diversas e complexas mudanças históricas. Sendo difícil enxergar uma história evolutiva e linear da mesma, ou mesmo uma linha teórica unívoca a respeito de seu fundamento e construção. A cultura de consumo, como toda cultura, está sujeita a contextos históricos e geográficos, bem como está sempre articulada com fatores sociais, políticos, econômicos, étnicos. Contudo, há aspectos que podem ser abordados por estarem constantemente presentes nesta cultura de consumo capitalista ocidental, por fazer parte de um sistema socioeconômico pensado e difundido. Ao debruçar-se sobre as lojas de departamentos para entender a estruturação do consumo moderno, Rocha esclarece:

$\mathrm{Na}$ realidade, os diferentes movimentos próprios de tempos anteriores até os grandes magazines do século XIX são mais reveladores quando pensados em termos de arranjos culturais que estruturam experiências análogas e contribuem para o aprofundamento da nossa compreensão sobre o tempo presente. Trata-se mais de um sistema de múltiplos planos entrelaçados, por vezes compatíveis, por vezes contraditórios, do que uma progressão linear da narrativa histórica. (ROCHA; FRID; CORBO, 2016, pp. 12-13).

Nesse sistema de múltiplos planos, alguns aspectos da cultura de consumo atual terão semelhanças, diferenças e novidades quando comparados com épocas passadas. Mas, em todas elas, há relação entre um arranjo cultural e a forma com a qual este se relaciona com os objetos ao seu redor. Por isso, algumas ideias e até técnicas de venda são bem semelhantes a do século passado, ou até mesmo, retrasado, já outras situações são totalmente novas. Por isso, para um melhor entendimento sobre a cultura de consumo, é necessário considerar algumas principais teorias surgidas sobre esta ao longo dos anos. 


\subsection{Teorias da cultura de consumo}

Nessa teia de sistemas que é a cultura de consumo, muitas teorias já foram desenvolvidas e a partir de diversas ideologias e perspectivas. $\mathrm{Na}$ dificuldade de abarcar este todo complexo, alguns teóricos enfatizaram o poder dos objetos de consumo, apontando para seu caráter simbólico ou até mesmo para a naturalização antropológica de uma sempre existente relação entre o ser humano e os objetos que o cercam. Outras autoras e autores se debruçaram sobre a mudança que a cultura de consumo causou na própria figura humana, que agora se transformou num consumidor. Outros ainda buscaram entender as mudanças das relações sociais numa cultura de consumo, pondo em relevo a importância do consumo na busca por status, distinção ou ascensão social.

São múltiplas as possibilidades teóricas da cultura de consumo. Interessante é a divisão feita por Mike Featherstone em seu livro "Cultura de consumo e pós-modernismo" (FEATHERSTONE, 1995). O autor distribui algumas teorias em três perspectivas consideradas fundamentais: a produção do consumo; modos de consumo; consumindo sonhos, imagens e prazeres.

Quanto à primeira expectativa, não há dúvidas de que o consumo atual está totalmente ligado ao modo de produção desenvolvido a partir da revolução industrial que o mundo experimentou no fim do século XIX. Através do sistema capitalista, a produção em massa fez surgir também o consumo em massa, que, logo, se tornaria uma forma global de relação entre a fabricação dos objetos de consumo e a sociedade.

Afirma-se que a expansão da produção capitalista, especialmente depois do impulso recebido da gerência científica e do 'fordismo', por volta da virada do século, necessitou da construção de novos mercados e da 'educação' de novos públicos consumidores por meio da publicidade e da mídia. (FEATHERSTONE, 1995, p. 32).

Isto é, não era necessário somente produzir bens de consumo, mas também ensinar a sociedade a consumir. Para a sustentação do sistema capitalista, eram necessárias a produção em massa do produto a ser consumido e a produção de uma massa consumidora (ou consumista). A sociedade precisava aprender a consumir. Daí o porquê de Featherstone chamar essa primeira perspectiva de "a produção do consumo". O 
consumo é produzido juntamente com seus objetos. A partir daí cria-se uma indústria cultural, na qual todos os valores culturais e pessoais são regidos pela lógica da produção capitalista.

As atividades de lazer, a arte e a cultura de modo geral são filtradas pela indústria cultural: a recepção é ditada pelo valor de troca à medida que os valores e propósitos mais elevados da cultura sucumbem à logica do processo de produção e do mercado. As formas tradicionais de associação na família e vida privada, bem como a promessa de felicidade e realização, "o anseio por um Outro totalmente diferente" que os melhores produtos da alta-cultura buscavam, são oferecidos como objetos inofensivos a uma massa atomizada, manipulada, que participa de uma cultura ersat ${ }^{4}$ produzida em massa e reduzida ao menor denominador comum. (FEATHERSTONE, 1995, pp. 32-33).

O termo "indústria cultural" foi criado e bem trabalhado por Theodor Adorno e Max Horkheimer, filósofos da escola de Frankfurt (ADORNO; HORKHEIMER, 1991). Os autores fazem uma dura crítica à forma como os meios de comunicação se tornaram um meio de manipulação em massa das vontades. A racionalização através da qual a indústria atribui valores aos produtos passam também a ser base de cálculo para todos os aspectos da vida, isto causa um empobrecimento cultural, pois suprime a liberdade de escolha e pensamento, que agora está limitada aos estímulos deliberativos da indústria. Essa é a cultura de consumo capitalista. "Ela é simplesmente a cultura do valor de troca e do cálculo instrumental-racional - algo que talvez pudesse ser designado como uma 'não-cultura' ou uma 'pós-cultura'?” (FEATHERSTONE, 1995, p. 33). O posicionamento de Adorno e Horkheimer, avesso à cultura de massa, os rendeu a crítica de carregarem em seu posicionamento certo elitismo. Não ocorreu o mesmo com Walter Benjamin, outro filósofo da escola de Frankfurt. Este enxergava na massificação industrial a possibilidade da democratização da arte, sobretudo pelo fato da nova participação das classes populares.

4 Ersatz, em alemão, significa "substituta". No sentido empregado aqui, a cultura produzida em massa atua como substituta da cultura aristocrata. A cultura de consumo visa alcançar todas as esferas da sociedade, reconfigurando (ou substituindo) seus desejos e valores simbólicos ao transformá-los em números. 
Há nos escritos de Benjamin um forte veio populista, que é muitas vezes contrastado com o propalado elitismo de Horkheimer e Adorno. Benjamin enfatizou o momento utópico, ou positivo, da produção de mercadorias para consumo em massa, que permitiu à criatividade se libertar da prisão da arte e migrar para a multiplicidade de objetos cotidianos produzidos em massa. (FEATHERSTONE, 1995, p. 44).

O campo da publicidade compreendeu o lugar da arte na produção do consumo. As embalagens, as imagens, os sons, os vídeos são meios de veiculação de sedução e sensações. Através deles, os objetos dão um salto qualitativo, passando a não serem mais coisas que foram criadas para devidas utilidades, mas, agora, ganham significados que estão para além de sua utilidade pragmática. Isso muda a forma como tais objetos são enxergados e, consequentemente, a forma como são consumidos. No sentido de uma teoria dos signos na cultura de consumo, destaca-se o pensamento do sociólogo e filósofo francês Jean Baudrillard (BAUDRILLARD, 1981; 2008). "A maior contribuição da teoria de Baudrillard é apoiar-se na semiologia para argumentar que o consumo supõe a manipulação ativa de signos. Isso se torna central na sociedade capitalista tardia, onde o signo e a mercadoria juntaram-se para produzir a "mercadoria-signo"” (FEATHERSTONE, 1995, p. 33).

Neste sistema, a mídia e a publicidade são meios de transferência de significados. Os responsáveis pela publicidade pensam quais significados culturais serão vinculados ao seu objeto: masculinidade, feminilidade, símbolos políticos, status social e estilos de vida. Por meio deles, serão transmitidos valores de poder, liberdade, segurança, vida saudável. Assim, associa-se valores culturais ao objeto produzido. A realidade é usada para se criar e se produzir uma "outra" realidade. Nos escritos de Baudrillard "a ênfase se desloca da produção para reprodução, para a reduplicação infinita de signos, imagens e simulações por meio da mídia, abolindo a distinção entre imagem e realidade" (FEATHERSTONE, 1995, pp. 33-34) Por, isso, a manipulação dos signos culturais ocupa um lugar de extrema importância na produção do consumo, da qual a cultura de consumo depende.

A segunda perspectiva trazida por Featherstone se concentra nos modos de consumo. Ou seja, a forma como são consumidos os objetos de consumo e seus significados culturais bem como a relação 
da sociedade com eles. Após a aquisição, o que é consumido ganha outras demarcações pessoais e sociais, podendo ganhar significados afetivos e familiares ou mesmo se tornar sinal de determinadas classes sociais e estilos de vida. Assim, então, coisas como roupas, carros, tênis, artigos esportivos, produtos cosméticos, obras de arte, estilos musicais, categorias de livros, se tornam indicativos de status social, poder aquisitivo ou até mesmo da personalidade de alguém. É muito comum classificarmos produtos e preferências como "coisa de rico", "coisas de pobre" ou "coisas de classe média". Por outro lado, existem objetos que ganham um valor afetivo que independem de seu valor de troca. Isto é muito comum em mobílias, joias e objetos que carregam esse valor afetivo por remeterem a algum familiar ou pessoa com quem se tem um vínculo sentimental.

É nesse sentido que podemos designar o aspecto 'duplamente' simbólico das mercadorias nas sociedades ocidentais contemporâneas: o simbolismo não se evidencia apenas no design e no imaginário embutido nos processos de produção e marketing; as associações simbólicas das mercadorias podem ser utilizadas e renegociadas para enfatizar diferenças de estilo de vida, demarcando as relações sociais. (FEATHERSTONE, 1995, p. 35).

O objeto de consumo continua a ter seu valor de troca dinamicamente modificado, depois de ser adquirido. Garrafas de vinho, obras de arte, carros, antiguidades, têm seu valor de troca constantemente alterado de acordo com o tempo de fabricação, a autoria da arte, o estado de conservação ou o antecedente de proprietários. Uma jaqueta de couro da década de 50 tem certo valor, contudo, se ela foi usada pelo Elvis Presley, a carga simbólica é completamente outra e, portanto, seu valor de troca também.

O economista e sociólogo estadunidense Thorstein Veblen foi pioneiro em enxergar o consumidor como alguém que tem uma relação para além da necessidade com seu objeto de consumo. Sua obra "A teoria da classe ociosa" (VEBLEN, 1988), publicada originalmente em 1899, já trazia a ideia de que através do consumo conspícuo, ou seja, do consumo como ostentação e demonstração de status, o indivíduo visava, não somente a utilidade pragmática que o bem oferecia, mas, sobretudo, a distinção social. Segundo, Fontenelle: 
Dessa perspectiva, o economista e sociólogo Thorstein Veblen (1988) pode ser considerado um precursor do marketing, uma vez que, em um livro originalmente publicado em 1899, apontou os limites da teoria do "valor-utilidade" dos neoclássicos e postulou a necessidade de se pensar o valor simbólico dos bens, portanto, o consumo como um ato social. Ao escrever sobre o consumo conspícuo, esse autor fez ver toda a importância de se considerar a questão da emulação, da distinção, da busca por diferenciação ao analisar comportamentos ligados ao consumo. (FONTENELLE, 2017, pp. 45-46).

A obra de Veblen é importante porque põe os estudos sobre o consumidor em outro patamar. Tira a ênfase, então posta pela economia, na necessidade biológica, para transcende-la e apontar para a dimensão simbólica e social. Assim, nas palavras de Lima sobre a teoria vebleniana: "o consumidor não é alguém que age em função do estômago, mas ele é alguém que tem pensamento simbólico.” (LIMA, 2010, p. 21).

Também sobre o papel simbólico e social dos bens, é igualmente importante o trabalho de Mary Douglas e Baron Isherwood intitulado "O mundo dos bens" (DOUGLAS; ISHERWOOD, 2006). A antropóloga e o economista dividem os bens de consumo em três grupos: O primeiro é formado pelo consumo relativo aos produtos do setor primário de produção (Alimentação); O segundo é constituído pelo consumo tecnológico relativos ao setor secundário (transportes, máquinas); O terceiro é constituído pelo consumo de informação relativos à produção terciária (livros, atividades de lazer e cultura, artes) (FEATHERSTONE, 1995, p. 37). Em todos os três grupos, o consumo está em relação direta com as articulações entre os papéis sociais dos indivíduos.

Em todas as sociedades, podemos dizer que as coisas, trocadas no interior de um amplo sistema de circulação de objetos, ideias e pessoas (...) transmitem mensagens fundamentais à participação dos sujeitos na vida social. Ao mesmo tempo, os objetos, ideias e pessoas trocados estabelecem e mantêm as relações sociais. (LIMA, 2010, p. 22).

Isto quer dizer que nesse sistema de circulação de objetos, a participação ou não dos indivíduos nos grupos de consumo expostos acima dirão a participação desse sujeito na sociedade bem como as relações sociais que ele estabelecerá. Partindo dessa afirmação básica, Douglas e Isherwood escrevem como esse sistema provoca e mantém a desi- 
gualdade social. Os mais pobres tendem a ficar limitados ao primeiro conjunto de bens de consumo (setor primário), tendo dificuldades de acesso ao consumo relativo ao setor terciário (informação, arte, lazer). E, "para atingir o topo das classes de consumo é preciso não somente um nível de renda mais elevado como também uma competência para julgar bens e serviços de informação que proporcione o feedback necessário do consumo para o uso, que é em si um requisito para o uso." (FEATHERSTONE, 1995, p. 37). Ou seja, além do acesso às informações e obras de arte, é necessário também ter algum conhecimento prévio para uma apreciação profunda delas. Em ambos os casos, os setores mais pobres se encontram em déficit, dificultando o movimento em direção à igualdade.

A dificuldade de acesso dos mais pobres ao consumo relativo aos setores secundários e terciários limita o tamanho de sua rede social. Isto encurta seu horizonte de vida, diminuindo as oportunidades de troca de informações e, consequentemente, também a possibilidade de maior participação na sociedade.

Em palavras mais diretas, podemos dizer que, quanto mais rico alguém é, mais bens ele tem pra trocar, sendo que mais trocas serão possíveis e com maior número de pessoas. Quanto mais as pessoas participam de rede de trocas, mais informações e oportunidades circulam por ela, o que leva à garantia da reprodução da riqueza para aqueles que dela participam. A divisão dos bens é profundamente expressiva da divisão social: ser proprietário de uma reserva mais elevada de recursos materiais significa estar em alta posição na hierarquia e, assim, estar mais qualificado e ter a possibilidade de manutenção de uma rede social mais abrangente. Esse feixe de interesses explica a importância atribuída pelos membros das esferas mais altas da sociedade ao controle e à proteção de seus bens. Inversamente, eis aí também uma direção para a compreensão da pobreza e da exclusão social. (LIMA, 2010, p. 24).

Isto significa que a pobreza nunca é meramente pobreza financeira. Junto a ela existem "outras pobrezas", tais como a pobreza de informações, criações culturais e possibilidades de vida. E estas últimas tendem a reafirmar a primeira, limitando o pobre a uma condição aprisionadora. "Finalmente, ser pobre é estar inserido em um ambiente muito recolhido e, no limite, pode mesmo significar isolamento. A segregação, dessa feita, implica exclusão não apenas de certo padrão de consumo e estilo 
de vida, mas, sobretudo, significa distância dos meios de informação e auxílio" (LIMA, 2010, pp. 24-25).

Ainda sobre a relação entre classes sociais e o consumo, é de extrema importância a obra "A distinção" (BOURDIEU, 2007), do sociólogo francês Pierre Bourdieu. Partindo de uma pesquisa qualitativa feita na França dos anos 1970, o autor escreve sobre o senso comum da época, o qual revela a existência de uma hierarquização do gosto. A obra do sociólogo revela a diferença de gosto entre as classes e como ele serve de parâmetro para classifica-las e hierarquiza-las. Para Bourdieu, "o gosto classifica, e classifica o classificador." (BOURDIEU apud FEATHERSTONE, 1995, p. 38). Contudo, na sociedade capitalista, os gostos das classes mais altas não são mais tão isolados como o eram no Antigo Regime. No capitalismo as pessoas são estimuladas a adquirirem os gostos das classes superioras e isso leva a uma "caça aos gostos", pois, enquanto a cultura de consumo estimula o novo consumo das classes trabalhadoras, as classes superiores buscam meios para manter sua distinção delas.

A oferta constante de novas mercadorias, objetos de desejo e da moda, ou a usurpação dos bens marcadores pelos grupos de baixo, produz um efeito de perseguição infinita, segundo o qual os de cima serão obrigados a investir em novos bens (de informação) a fim de reestabelecer a distância social original. (FEATHERSTONE, 1995, p. 38).

O terceiro grupo de consumo apontado por Douglas e Isherwood (consumo de informação, cultura, arte) será o ponto de investimento das classes superiores para marcar sua posição social. Esse conjunto de informações é visto como bens culturais que sinalizarão a maneira correta de consumo dos bens materiais. Não basta ascender financeiramente, há também de se aprender a se comportar como alguém da classe superior. Somente o gosto pelos objetos condizentes à classe não é suficiente, também é necessário dominar o código por trás desse gosto, através do conhecimento de seus significados simbólicos. O gosto da classe superior é formado pela posse dos bens materiais como também pelo domínio dos bens culturais. Este gosto sempre prezará pela estética e pela sofisticação, enquanto que, por outro lado, o gosto das classes mais baixas será marcado por formas mais toscas e diretas. 
Assim, seguindo o parâmetro do gosto, seria possível hierarquizar os bens e, por conseguinte, seus consumidores. Colocados lado a lado, bens e pessoas, seria possível perceber que os bens, hierarquizados, correspondem à hierarquização social. Entre os mais ricos e educados, encontram-se aqueles que têm gosto para consumir com bom gosto. $\mathrm{Na}$ base da pirâmide social, pessoas sem uma boa educação e desprovidas de gosto supostamente consomem bens de mau gosto. (LIMA, 2010, pp. 27-28).

Contudo, na cena da cultura de consumo atual, a confusão dos gostos está em alta e dá lucro. Para isso, é importante a participação de profissionais (designers, profissionais da moda, publicitários), mídias (jornais, revistas, televisão, rádio - e, hoje, a internet) e pessoas públicas. Esses agentes da cultura de consumo, denominados por Bourdieu como "os novos intermediários culturais", serão os propagadores de certo estilo de vida, eles "enfatizam o aperfeiçoamento, desenvolvimento e transformação pessoais, como administrar propriedades, relacionamentos e ambições, como construir um estilo de vida realizador." (FEATHERSTONE, 1995, p. 38). Esses intermediários culturais impulsionam a comercialização não somente dos bens materiais, mas também dos bens simbólicos, a fim de fazê-los chegar a um número maior possível de consumidores, mantendo, contudo, o significado de status que esses bens possuem.

Mesmo levando em conta todo sistema da cultura de consumo com sua propagação de um estilo de vida de sucesso, Bourdieu afirma que é totalmente possível a distinção entre as classes, através de uma leitura de comportamentos.

Os estilos e marcas diferentes de roupas e produtos da moda, conquanto estejam sujeitos a mudança, imitação e cópia, constituem um conjunto de pistas usado no ato de classificar os outros. Como nos lembra Bourdieu com seu conceito de capital cultural, os sinais das disposições e esquemas classificatórios que revelam as origens e a trajetória de vida de uma pessoa manifestam-se também na forma do corpo, altura, peso, postura, andar, conduta, tom de voz, estilo de falar, senso de desembaraço ou desconforto com o próprio corpo, etc. Assim, a cultura é corporificada, e isso não é apenas uma questão de quais roupas são usadas, mas também de como são usadas. (...) Assim, os novos-ricos, que podem adotar estratégias de consumo conspícuo, são identificáveis e postos em seu lugar no espaço social. Suas práticas culturais sempre correm o risco de serem depreciadas como vulgares e de mau gosto pela classe alta dominante, a 
aristocracia e os "ricos em capital cultural". (FEATHERSTONE, 1995, pp. 39-40).

Passando por Veblen, Douglas e Isherwood e Bourdieu, é possível ter uma noção de como a perspectiva do "modo de consumo", apontada por Featherstone é importante para entender a cultura de consumo. A forma com que a sociedade passa a se relacionar com os objetos de consumo têm influência direta em sua própria organização como sociedade. As relações entre as classes sociais, a mídia, a indústria cultural foram totalmente transformadas pelo modo como o consumo se dá na cultura de consumo. E, nesse processo de consumo, é de suma importância a reflexão sobre a terceira perspectiva teórica intitulada por Featherstone como "consumindo sonhos, imagens e prazeres".

Ao mencionarmos a teoria de Colin Campbell acerca do papel do Romantismo na cultura de consumo, e também as técnicas de venda das lojas de departamentos, ficou claro que a formatação básica da cultura de consumo a partir do século XIX já trazia consigo a importante consideração de que os objetos de consumo eram possíveis lugares de projeção dos desejos e sonhos das pessoas. Já foi considerado também que a dimensão desejosa, onírica, lúdica do ser humano tem sido bem explorada na produção do consumo. Tal produção, então, passou a não pensar somente na mera utilidade de um objeto, mas também no possível lugar que este pode ocupar nessas demandas humanas de desejo.

A socióloga Isleide Fontenelle destaca como as teorias psicanalíticas de Freud foram importantes para o aumento do consumo nos Estados Unidos no início do século XX. Nesta época, foi criada uma nova profissão chamada "relações públicas", cujo objetivo era prestar um serviço de consultoria às organizações, no qual se faria uma análise da sociedade e se montaria uma estratégia para produzir novos consumidores. O inventor dessa nova profissão foi Edward Bernays. Ele era sobrinho de Freud e, portanto, estava familiarizado com a teoria freudiana sobre o desejo humano, fazendo uso dela para seu objetivo como profissional das relações públicas. É atribuída a ele a frase que resume bem esse objetivo: "Produzir consumidores, esses seres especiais que não necessitam daquilo que desejam e não desejam aquilo de que necessitam.” (FONTENELLE, 2017, p. 34). Fontenelle diz: 
Bernays acreditava na importância que esse novo campo do conhecimento teria no processo de produção de consumidores, na medida em que apelasse ao poder ilimitado do desejo humano. Por isso Bernays propunha que para instigar a compra era preciso focar não nas necessidades das pessoas, no seu lado racional, mas nas suas fantasias e nos seus desejos muitas vezes inconfessáveis. Tendo em visa que uma consideração central em psicanálise é que o desejo é produzido pela cultura, a ideia básica de Bernays era a de dar forma ao desejo humano mediante sua associação a objetos de consumo. (FONTENELLE, 2017, p. 35).

A partir da teoria freudiana, o profissional das relações públicas buscava, então, elementos sociais que servissem como meios de concretização de seus objetivos comerciais. Fontenelle menciona um trabalho de Bernays que se tornou um paradigma da articulação entre psicanálise, sociedade e consumo. Um fabricante de cigarros recorreu a Bernays para que quebrasse o tabu masculino de que mulheres não podiam fumar, sobretudo em público. Após consultar um psicanalista, Bernays foi orientado de que era necessário dar ao ato de fumar o significado de protesto contra o poder dos homens. O ano era 1929, uma década marcada por reivindicações e conquistas femininas nos Estados Unidos, Bernays então contrata vinte mulheres que representavam o movimento de emancipação feminina para que puxassem cigarros e isqueiros de suas bolsas e acendessem um cigarro em pleno desfile de Dia de Ação de Graças, em Nova York. Naturalmente, o ato repercutiu em toda mídia e, a partir desse dia, o cigarro passa a configurar um símbolo da emancipação feminina. (FONTENELLE, 2017, pp. 37-39). "Esse 'acontecimento cultural' ocorreu em 31 de março de 1929. E o que Bernays fez foi lançar mão de certo desejo da época: o desejo feminino por liberdade, por igualdade de direitos" (FONTENELLE, 2017, p. 38).

Feathersone aponta que a manipulação dos desejos e o incentivo ao excesso, característicos da cultura de consumo, convivem em tensão com a visão do consumo como um ato comedido auxiliador de uma prática trabalhista ascética e individualista herdada da pequena burguesia do século XIX e do tatcherismo do século XX. A cultura de consumo capitalista, sobretudo a que se desenvolve nos Estados Unidos, muda o paradigma dos modos racionalistas de consumo, pois é desenvolvida 
sobre o excesso e não se furta em lançar mão de instrumentais simbólicos para associá-los ao ato de consumo.

Isso é devido a sua capacidade de ampliar e questionar as noções vigentes de consumo, pondo em circulação imagens de consumo com sugestões de prazeres e desejos alternativos, do consumo enquanto excesso, desperdício e desordem. Isso ocorre numa sociedade na qual (...) grande parte da produção é voltada para o consumo, lazer e serviços e na qual se verifica uma relevância crescente da produção de bens simbólicos, imagens e informação. (FEATHERSTONE, 1995, p. 41).

Nas tradições culturais nas quais o consumo é com base na racionalização, havia formas de canalização desse excesso. Ou seja, ocasiões em que o comedimento e a formalidade davam lugar à transgressão ao afloramento dos desejos. Os carnavais, as feiras e os grandes banquetes eram alguns desses locais. Por outro lado, a cultura de consumo comercializa esse excesso. Ele é parte importante dela. O acúmulo de energia gerado pela avalanche de informações, imagens e produtos geram outros tipos de mercados, o do entretenimento, do espetáculo, dos parques temáticos e do mundo do consumo conspícuo (ostentação).

De acordo com a noção de economia de Bataille, a produção econômica não devia ser associada à escassez, mas ao 'excesso'. Com efeito, a destruição torna-se o objetivo da produção, e o problema-chave passa a ser o que fazer com la part maudite (a parte maldita), o excesso de energia traduzido num excesso de produtos e mercadorias, um processo de crescimento que alcança seus limites na entropia e na anomia. Para controlar efetivamente o crescimento e administrar o excedente, a única solução é destruir ou esbanjar o excesso em forma de jogos, religião, arte, guerras, morte. Isso se faz por meio de trocas de presentes, potlaches, torneios de consumo, carnavais e consumo conspícuo. De acordo com Bataille, as sociedades capitalistas tentam canalizar la part maudite para o crescimento econômico pleno, de modo a produzir o crescimento infinito. (FEATHERSTONE, 1995, p. 42).

Featherstone afirma que, nesses locais nos quais o excesso é destruído/esgotado, ocorre uma desordem ordenada, pois o afloramento dos desejos é canalizado para eles. O desejo também faz parte do mercado. E parece que quanto mais os objetos e experiências mexem com a dimensão do desejo, mais presentes estão as imagens e outros elementos 
que apontam para além da existência material do objeto de consumo. Desde as lojas de departamentos, o apelo à fantasia tem levado os consumidores não somente à experiência da compra, mas à compra como uma experiência toda cheia de elementos anexos. Entrar numa loja tem que proporcionar a sensação de entrar no mundo dos sonhos, para a qual é necessária a participação da urbanização, dos meios de transporte, das mídias, da propaganda, do marketing, de intermediários culturais (pessoas públicas, especialistas), todos eles com a missão de estetizar a experiência da compra. ${ }^{5}$

Nesse mundo estetizado das mercadorias, as lojas de departamentos, galerias, bondes, trens, ruas, a trama de edifícios, e as mercadorias em exposição, além das pessoas que perambulam por esses espaços, evocam sonhos parcialmente esquecidos à medida que a curiosidade e memória do passante é alimentada pela paisagem em constante mutação, onde os objetos aparecem divorciados de seu contexto e submetidos a associações misteriosas, que são lidas na superfície das coisas. A vida cotidiana das grandes cidades torna-se estetizada. (FEATHERSTONE, 1995, p. 44).

Somente a arte é capaz de dar conta de desejos profundos e nem sempre racionalizados. A cultura de consumo tem papel fundamental para estetização da vida que tomou conta do ocidente no século XX, pois foi ela quem abriu as portas para que a arte também ingressasse à indústria. $\mathrm{O}$ designer industrial se tornou profissão imprescindível ao pensar e elaborar a materialização de um produto, o que levou o crítico cultural e jornalista britânico Stephen Bayley a afirma que "o design industrial é a arte do século XX" (BAYLEY apud FEATHERSTONE, 1995, p. 46). Essa parceria proporcionou a quebra da barreira entre a arte e a vida cotidiana das massas. Contudo, o deslocamento da arte para a indústria não foi responsável sozinho pela quebra dessa barreira. Soma-se a ele o movimento artístico vanguardista, que, através do dadaísmo, do surrealismo e do pós-modernismo, visou quebrar padrões artísticos tradicionais usando elementos do cotidiano para fazer arte. Foi assim que, mictórios, pás de retirar neve e garfos tornaram-se elementos presentes em pinturas e esculturas. Então, ao longo do século

5 Sobre a estetização da sociedade, ver: (LIPOVETZKY; SERROY, 2015) e (BAUDRILLARD, 1981). 
$\mathrm{XX}$, a arte estava na industrialização de objetos cotidianos enquanto que a vida cotidiana também estava na arte.

A pop-art, movimento iniciado na década de 50 na Inglaterra e que ganha proeminência nos Estados Unidos da década de 60, passou a retratar de forma irônica esse laço entre a arte e a indústria, sendo considerada paradigmática a obra de Andy Warhol na qual o artista reproduz 32 latas de sopa Campbell em 32 quadros, organizando-os na galeria em fileiras horizontais com o objetivo de simular as prateleiras dos supermercados.

A partir desse movimento duplo: a industrialização $d a$ arte e a industrialização $n a$ arte, o papel dos símbolos na cultura de consumo se intensificou. Eles são responsáveis por envolver o consumidor através da produção de desejos, sonhos e prazeres, fazendo uso de imagens, pessoas e sons. Esses desejos nunca são saciados, pois o caráter ilimitado da produção do consumo se encarrega de produzir novos desejos. Nas palavras de Maria Clara Bingemer: "O mercado funciona como um elemento que cria necessidades fictícias através de mecanismos da publicidade e da exibição social. No fundo o que se consome não são tantos objetos, mas as sensações." (BINGEMER, 2013, p. 200). E mais a frente: "A vida humana, nesse contexto, acontece então em meio a um caleidoscópio multiforme e multicolor de objetos e sensações, onde as peças são movidas como em um jogo constante e fugidio. Viver equivale a consumir novidades em um processo sem fim." (BINGEMER, 2013, p. 201).

Esta terceira categoria teórica sugerida por Featherstone aponta para o que sustenta, hoje, a cultura de consumo, a saber, o uso dos símbolos, dos significados por trás dos objetos. O consumo se tornou ponto de escape na perda de referências e estabilidades que caracterizam a pós-modernidade. E, há de ser estudada também a possibilidade de participação da cultura de consumo na formação do quadro pós-moderno. Afinal, a intensa busca por um substituto para as antigas certezas religiosas e por novas mediações sociais parecem ser também interessantes para a manutenção da cultura de consumo. Na carência de símbolos e discursos sólidos, nos chama a atenção o que escreve Rubem Alves: 
Não compramos coisas em função de sua utilidade, mas em função do seu valor simbólico. Se comprássemos as coisas porque elas são úteis estaríamos nos mantendo rigorosamente no nível das suas propriedades materiais. Acontece que as coisas são desejadas, produzidas e compradas por aquilo que elas dizem. Não é verdade que garrafas de vinho, roupas, automóveis, livros, viagens turísticas, quinquilharias eletrônicas e cigarros são mensagens, tendo por isso mesmo uma dimensão sacramental? O homem não vive só de pão...( ALVES, 2009, p. 57).

Muitas outras dimensões e teorias acerca da cultura de consumo já foram observadas e elaboradas. A nossa intenção, aqui, não foi esgotar o assunto, mas trazer os principais fatores históricos e linhas de investigação acerca da cultura de consumo. A pesquisa sobre a cultura de consumo vem crescendo ao longo dos últimos anos. No início do século $\mathrm{XX}$, estudar consumo era tarefa apenas de empreendedores e profissionais de relações públicas. A partir do pós-II Guerra este interesse se amplia. Somente na década de 60 , as pesquisas no campo do marketing vão ganhando conotação mais científica, através de especialistas em ciências quantitativas e sociais. Após uma série de evoluções no estudo do consumo, em 2005, é publicado no Journal of Consumer Research um artigo de Eric Arnould e Craig Thompson intitulado "Consumer culture theory (CCT): twenty years of research" (Teoria da cultura do consumidor: vinte anos depois) (ARNOULD; THOMPSON, 2005, pp. 868-882). Este artigo marca a criação de um novo campo de pesquisa chamado Consumer Culture Theory (CCT), que, foi construído ao longo de vinte anos de pesquisa e cujo objetivo é considerar que, devido à complexidade da relação do ser humano com o consumo, é necessário ir além dos dados quantitativos ou mesmo qualitativos desta relação, levando também em consideração os vários olhares de outros campos do saber sobre ela. Sendo assim, o esforço da CCT é reconhecer a importância e a necessidade da transdisciplinaridade para se entender a cultura de consumo. A criação da CCT, portanto, abre espaço para que, dentre outras análises, a teologia também possa dar alguma contribuição. ${ }^{6}$

6 Para um panorama acerca dos estudos sobre consumo ver (PINTO; BATINGA, 2018, pp. 31-58). 


\section{Teologia da cultura}

\subsection{Teologia e Cultura}

Para podermos falar de uma teologia da cultura, é necessário, primeiro, uma reflexão acerca das significações modernas do próprio conceito de "cultura". Um conceito que nasce na modernidade e assume importante papel no desenvolvimento e nas estruturas de um mundo moderno. Pensar atualmente o tema da cultura é inevitavelmente remeter-se a um protagonismo universal humano transformador e autoconsciente que se descobre, aflora e desenvolve no período moderno. "Entende-se geralmente por modernidade um modo de civilização que se desenvolveu na Europa ocidental a partir do século XVI, com o Humanismo renascentista e a Reforma Protestante e encontrou seus fundamentos filosóficos e políticos nos séculos XVII e XVIII, com o pensamento empirista, racionalista e iluminista." (HIGUET, 2005, p. 9). Contudo, teve "seu apogeu no fim do século XVIII com dois acontecimentos decisivos: a revolução industrial e a revolução democrática." (HIGUET, 2005, p. 9). Nesse período, nesse mesmo contexto europeu, está inserido o ponto alto do conflito entre religião institucional e estado. Ao longo do século XIX, potencializa-se a emancipação humana intelectual, cósmica e política de uma cosmovisão divina, religiosa e mesmo metafísica, o que seria o início de uma grande onda ateísta. Contudo, na primeira metade do século XX, toda altivez humana é fortemente abalada pela eclosão de duas devastadoras guerras mundiais.

Muito ainda se reflete sobre os "longos passos" dados pela humanidade ao longo da modernidade, inclusive acerca de alguns recentes e atuais "retrocessos" ou "reavaliações". Entretanto, fato é que em nenhum outro período histórico, houve, da parte do ser humano, tão difundida consciência e exploração criativa de sua autonomia. O ser humano se percebe como agente participante, construtor e protagonista de sua própria história. Sem esse aporte histórico e filosófico, não é possível entender o que está no fundamento do conceito de cultura. A reflexão hodierna sobre o tema está substancialmente ligada às reflexões acerca das potencialidades do espírito humano. Rubem Alves, ao mencionar o termo cultura, o descreve como "nome que se dá a esses mundos que 
os homens imaginam e constroem.” (ALVES, 2009, p. 20). É inegável que, na modernidade, muito se imaginou e muito se construiu.

O termo teologia da cultura já traz em si uma tensão. Pois, falar de cultura, após "longa caminhada" de modernidade, é necessariamente levar em conta seu caráter criador, libertador, emancipador. Emancipação, sobretudo, da esfera religiosa, cuja leitura de mundo e cosmovisão vão, cada vez mais, sendo postas em questão e se distanciando das esferas públicas. São frutos dessa emancipação a secularização e a laicização, que marcam o "distanciamento" do divino das diversas esferas da cultura humana. O que, em termos religiosos, significa a divisão entre o "sagrado" e o "profano", ou "secular". A partir daí, algumas questões podem ser postas: Seria possível fazer teologia a partir de uma cultura "secular"? Estaria a reflexão teológica restrita somente às esferas culturais ligadas ao "sagrado"? As dimensões do "sagrado" e do "profano" são fundamentalmente opostas e estanques? Dentro de quais ressalvas, é possível uma teologia da cultura?

Muitas filosofias e teologias foram produzidas a partir dessa tensão- ruptura entre o universo religioso e a cultura secular. Algumas rumaram a uma síntese entre as partes, enquanto outras reforçaram a diferença entre as duas "naturezas". Na filosofia de Hegel (1770-1831) e na teologia de Schleiermacher (1768-1834) já “domina o projeto de uma reconciliação, de uma mediação entre a religião e a cultura, entre a teologia e a evolução científica moderna." (HIGUET, 2005, p. 18). Seguirão este caminho também os autores da chamada "teologia liberal", da escola de Albrecht Ritschl (1822-1889), da qual faziam parte Adolf Von Harnack (1851-1930) e Ernst Troeltsch (1865-1923), "que tinha como órgão a revista Christliche Welt, fundada em Berlim em 1877, a qual se propunha encarar os novos problemas do mundo e da sociedade numa perspectiva evangélica e servir de intermediário entre o mundo dos eruditos e os resultados da investigação de uma teologia que se queria crítica" (GIBELLINI, 1998, p. 19). Em oposição a este caminho de conciliação estava a chamada "teologia dialética", que tinha como principais nomes os teólogos Emmil Brunner (1889-1966) e Karl Barth (1886-1968). “A teologia dialética, portanto, não é uma Vermittlungstheologie - uma teologia conciliadora como (...) a teologia liberal - que 
tente harmonizar Deus e o homem, fé e cultura, e sim uma teologia que procede por contraposições dialéticas" (GIBELLINI, 1998, p. 23).

Numa terceira via, o filósofo e teólogo alemão Paul Tillich (18861965) "encontrou um caminho próprio, em diálogo com a filosofia da religião.” (HIGUET, 2005, p. 19). Para ele, não há ruptura entre religião e cultura secularizada. Mas, ambas estão substancialmente relacionadas. Para Tillich, a religião não é uma manifestação cultural dentre outras, mas, sim, a dimensão de profundidade do ser humano, uma dimensão que se apresenta ao ser humano como preocupação última acerca de sua própria existência e que, portanto, se manifesta através de toda e qualquer criação cultural humana que expresse tal profundidade. Nesse sentido, Tillich supera a pré-conceituação que tem por sagrado tudo aquilo que pertence ao âmbito do religioso e por secular tudo aquilo que não pertence. Se a cultura é criação do espírito humano, ainda que seja moderna e secularizada, ela pode expressar uma dimensão religiosa, contanto que tal dimensão esteja presente nela. Afinal, como disse o próprio Tillich em sua célebre frase: "religião é a substância da cultura e a cultura é a forma da religião." (TILLICH, 2009, p. 83). Não existe religião fora de uma manifestação cultural, ao passo que uma cultura sem sua profundidade religiosa se torna vazia. Assim, para superar o abismo entre a cultura secular e a dimensão da fé, Tillich recorre a uma análise ontológica da cultura, ou seja, a uma reflexão acerca do ser da cultura. Este, por sua vez, está diretamente ligado ao ser do próprio ser humano, visto que ele é o único ser capaz de fazer cultura e, sendo consciente disso, "criar um mundo dentro do mundo".

Assim, o fundamento da teologia da cultura é um desdobramento da ontologia do ser humano. Na direção desse fundamento está a pergunta sobre a unidade ontológica da cultura: qual o princípio antropológico da criação cultural? Quando dizemos que o ser humano é o único animal que cria seu próprio universo de significação é na cultura que vamos encontrar o ato e a forma da expressividade humana como ser histórico. (TILLICH, 2009, pp. 19-20).

Portanto, a teologia da cultura de Tillich é uma análise religiosa de uma cultura que se efetiva nas diversas criações culturais do ser humano na história, como na política, filosofia, psicologia, artes visuais, 
música, dança. Desta feita, mesmo uma manifestação cultural secular pode ser religiosa, ao passo que nem toda manifestação religiosa o é de fato. Sendo assim, a ideia tillichiana de uma "teologia da cultura" era um olhar sobre todas as criações do espírito, procurando nelas sempre o direcionamento humano ao incondicionado. Tillich acreditava que todas as manifestações culturais humanas tinham o potencial de revelarem essa dimensão religiosa do espírito humano. Esse é o cerne da postura tillichiana diante das criações culturais humanas. Com base nela, o autor construirá sua teologia da cultura.

\subsection{Teologia da cultura}

"Teologia da cultura" (Theology of Culture) é o título de um livro lançado em 1959. (TILLICH, 1959). Quando o autor o lança, já havia passado dos setenta anos de idade e já estava radicado nos Estados Unidos havia 26 anos. Este livro é uma coletânea de artigos que já haviam sido publicados anteriormente. Nele, "vários dos seus textos mais importantes sobre a teologia da cultura foram publicados pela primeira vez em inglês, junto com textos já publicados em diferentes lugares e agora reunidos nesta coletânea." (MUELLER; BEIMS, 2005, p. 36). Contudo, quando se menciona a teologia da cultura de Tillich, não é desta obra que se fala. A teologia da cultura de Tillich é um nome que se dá para o fazer teológico dele, ou seja, uma expressão que revela um princípio que guiará toda a sua construção teológica. Tillich é teólogo da cultura já muito antes do lançamento do livro "Teologia da Cultura". A proposta fundamental de uma teologia da cultura faz sua primeira aparição pública em uma conferência proferida na Alemanha em 1919 para a Sociedade Kantiana de Berlim. A conferência recebe o título Über die Idee einer Theologie der Kultur (Sobre a ideia de uma Teologia da Cultura). Nela, surge o fundamento de uma teologia que será desenvolvida ao longo de uma vida inteira.

Por isso, para que a teologia da cultura de Tillich seja compreendida, é preciso primeiramente observar quais foram suas inspirações e raízes, para apontar seus fundamentos, e posteriormente, ao menos citar os principais conceitos que foram surgindo e construindo sua estrutura. Para fazer este caminho, é preciso apontar desde aspectos biográficos a conceitos teológicos e filosóficos. O pensamento tillichiano é transdisci- 
plinar e carrega consigo considerável complexidade. A correlação com a filosofia sempre esteve presente na teologia tillichiana, e, ao longo do tempo, outras relações foram sendo tecidas à sua teologia, tais como, a relação com a ciência política, a sociologia, a arte e a psicologia.

Tillich provinha de família tradicional burguesa da aristocracia prussiana. Seu pai era pastor luterano que gozava de boa posição dentro da instituição, o que fez com que Tillich não soubesse o que era a dificuldade de uma vida pobre. Contudo, no período entre 1912 e 1914, após concluir seus estudos universitários e ser consagrado ao ministério pastoral, Tillich trabalhou como pastor assistente numa paróquia em Berlim. Lá, ao ministrar o Ensino Confirmatório em um bairro pobre da cidade, se deparou com a pobreza de forma vivencial. Isto fez com que a teologia de Tillich fosse tocada de forma permanente por uma preocupação acerca da realidade humana, sobretudo acerca das questões sociais. Como consequência dessa preocupação, o teólogo formou um grupo que se reunia regularmente acerca do tema "Cristianismo e Cultura". Outro impacto biográfico crucial para que Tillich se voltasse à realidade cultural de sua época foi sua participação como capelão na I Guerra Mundial. Diante das tragédias e das mortes, Tillich se via desafiado pela falta de sentido que a guerra lhe provocava. Além de ouvir e compartilhar das histórias de seus colegas advindos das diversas classes sociais do país. Como diz o próprio Tillich:

Já nas primeiras semanas, meu entusiasmo inicial desapareceu. Após alguns meses, eu estava convencido de que a guerra representaria a ruína total da Europa. Eu vi que a unidade era uma ilusão, que a nação estava dividida em classes e que as classes proletárias consideravam a igreja uma inquestionável aliada dos grupos dominantes. (TILLICH apud CALVANI, 2010, p. 17).

Após a I Guerra Mundial (1914-1918), Tillich inicia sua carreira acadêmica e já em 1919 publica dois importantes textos, sendo o primeiro, o texto germinal de sua teologia da cultura e que, por isso, merecerá olhar mais acurado na próxima sessão deste ensaio. O texto recebeu o título Über die Idee einer Theologie der Kultur (Sobre a ideia de uma Teologia da Cultura). Nele, o autor expõe sua opinião sobre o que é teologia e qual tarefa esta deve exercer. E ele o faz a partir 
da relação intrínseca que ele defende haver entre o saber teológico e a filosofia da religião. Um olhar mais específico sobre este texto será lançado no próximo tópico.

O segundo texto, publicado ainda em 1919, é intitulado Der Sozialismus als Kirchenfrage (O Socialismo como Questão para a Igreja), é a aplicação da teologia da cultura no campo político. Nele, há uma tentativa tillichiana de encurtar a longa distância entre as igrejas luteranas e o movimento político socialista. O movimento socialista era visto, majoritariamente, como um movimento ateu, enquanto que a igreja, a nível oficial, procurava não envolver seus conceitos teológicos com as críticas sociais feitas pelos filósofos socialistas. Por isso, neste texto, o teólogo busca expor que "o socialismo não é coisa de 'ateus', mas que resgata importantes tarefas próprias do cristianismo bem entendido, e nesse sentido representa uma pergunta ou questão para a igreja, tanto no sentido de uma finidade de propósitos como até de crítica para a própria igreja, quando esta se desvia de sua missão" (MUELLER; BEIMS, 2005, p. 21).

A década de 1920 foi muito produtiva para a teologia de Tillich. Em muitos textos produzidos nesse período, variavam-se os temas, mas sempre um mesmo espírito permanecia, a saber, o de aproximar a teologia à realidade cultural da sociedade em que ele estava inserido, sobretudo no campo político. Para isso, Tillich percorreu tanto o caminho da teologia mesma quanto da filosofia da religião. Em 1922, Tillich publica um texto com o título Kairos. Onde o autor traz a importante noção da ação do eterno na história. Esse será um importante conceito dentro da teologia da cultura tillichiana e que será aprofundado ao longo dos anos. No mesmo ano, é publicado Die Überwindung des Religionbergriffs in der Religionsphilosophie (A superação do conceito de religião na filosofia da religião), no qual ele traz a noção de religião como experiência transcendente na imanência. Em 1923, ele publica Grundlinien des religiösen Sozialismus (Linhas-Mestras do Socialismo Religioso), onde ele traz sua concepção acerca de um programa desse movimento. Em 1924, o autor publica Kirche und Kultur (Igreja e Cultura), texto no qual convoca a igreja e a teologia a levar a cultura a sério. E assim, ao longo dos anos 20, vão surgindo outros textos como Das Dämonische: Ein Beitrag zur Sinndeutung der Gechichte (O 
Demônico: uma contribuição à interpretação do sentido da história), em 1926, e Gläubiger Realismus ("Realismo Crente"), em 1927, que, além de trazerem uma leitura da conjuntura "mundial" de sua época, contêm conceitos importantes que estruturarão uma teologia da cultura tillichana, como "demônico", que seria o uso das manifestações culturais que, apesar de partirem de uma posição criativa, e portanto, positiva, são usadas de forma negativa para a destruição. E o "realismo crente", que é olhar para a realidade com o olhar religioso sem, contudo, distorcer a realidade.

Em 1933, Tillich lança o livro Die Sozialistische Entscheidung (A Decisão Socialista), “imediatamente proibido e recolhido pelo governo nacional-socialista. Este livro acabou sendo o motivo formal de sua demissão da Universidade de Frankfurt pelo regime de Hitler." (MUELLER; BEIMS, 2005, p. 29). Com o cerco nazista se fechando, neste mesmo ano, Tillich teve que se exilar nos Estados Unidos mesmo não sendo de sua vontade. Em seus anos, lá, Tillich continuou a desenvolver sua teologia da cultura, trabalhando a relação da teologia com a psicologia, a arte, a arquitetura e até mesmo a área da saúde. No início da década de 60, Tillich faz uma viagem ao oriente e se aprofunda no tema do diálogo inter-religioso, tendo como apoiador nessa reflexão o estimado cientista das religiões Mircea Eliade. Tillich morre em Chicago no dia 22 de outubro de 1965. (MUELLER; BEIMS, 2005, pp. 36-37).

A produção de Tillich é vasta e importante, sobretudo a respeito de uma aproximação da fé e da teologia com o espírito humano e suas criações (cultura). A teologia da cultura tillichiana é formada por muitos conceitos e nuances que ajudam, não somente entender a época vivida por ele, mas, também, se debruçar sobre o tempo atual, no qual uma interpretação religiosa da cultura, ou uma teologia da cultura, não tem ainda o destaque devido. Portanto, por uma necessária escolha metodológica, nos delimitaremos ao texto inaugural de sua teologia da cultura.

\subsection{O início de tudo: "Sobre a ideia de uma teologia da cultura"}

Em 16 de abril de 2019, completou cem anos da conferência que Tillich proferiu à Sociedade Kantiana de Berlim com o título: Sobre a ideia de uma teologia da cultura. Esta conferência pode ser considerada o ponto inicial de sua teologia da cultura, visto que, é nela que Tillich 
trabalha a relação de religião e cultura pela primeira vez. Este texto é o marco oficial de uma teologia que vai ganhando corpo e capilaridade ao longo da carreira do teólogo. Devido à importância desse texto, então, é valido trazer suas afirmações basilares, que fundamentam a teologia da cultura. ${ }^{7}$

Na primeira parte de seu texto, Tillich visa definir o que é teologia para ele. Nesta época, o estudo sobre a religião e o sagrado estava em alta. Rudolf Otto havia pulicado seu livro "O sagrado" havia apenas dois anos. Talvez, por isso, Tillich tenha escolhido, para esclarecer seu conceito de "teologia", traçar um paralelo entre a teologia e a filosofia da religião. Sendo assim, ele inicia apontando as diferenças hermenêuticas que existem entre algumas ciências, para, por fim, apontar as diferenças entre aquelas. Ele diz:

Nas ciências experimentais, devemos ir além do ponto de vista no qual nos encontramos. É a realidade que é a medida da verdade, e a realidade é uma. De dois pontos de vistas contraditórios, somente um pode ser verdadeiro, ou os dois podem ser falsos. Isso é o progresso da pesquisa científica que decide. (TILLICH, 1990, p. 31).

Já, no campo que ele chama de "ciências sistemáticas da cultura", isto é, aquelas ciências que partem sempre de acontecimentos históricos e criações culturais, a abordagem hermenêutica é diferente. O cientista que estuda manifestações culturais, sempre partirá de seu ponto de vista histórico. Os julgamentos de "verdadeiro" ou "falso" já não cabem mais aqui. De igual modo, não cabe uma tentativa de buscar conceitos universais absolutos para que, ignorando como as coisas se dão culturalmente, julgue tais manifestações culturais.

Uma estética gótica e uma estética barroca, uma dogmática católica e uma dogmática protestante moderna, uma ética romântica e uma ética puritana não podem jamais serem simplesmente etiquetadas como verdadeiras ou falsas. Por isso é igualmente impossível fabricar conceitos universais que sejam utilizáveis para explicar ideias culturais. (TILLICH, 1990, p. 31).

7 Usaremos, aqui, a versão francesa de Nicole Grondin em (TLLICH, 1990). Tradução nossa. 
Conceitos universais só são aceitáveis se postos sempre em relação com a experiência cultural. Eles não podem carregar para si caráter absoluto, como se não tivessem partido sempre de um ponto histórico específico, contudo, sua universalização sempre será para uma melhor compreensão do real. O universal é o a priori que se busca acerca das manifestações concretas, isto é, os conceitos mais vastos para abranger o máximo de situações reais possível. Nas "ciências sistemáticas da cultura", a busca pelo universal é papel da "filosofia da cultura". Por outro lado, há uma ciência que busca sistematizar as manifestações culturais, tentando normatizar seus objetos de estudo através de certos conceitos. Esta é a tarefa da "ciência normativa da cultura".

Daí a distinção que deve ser feita entre, de um lado, a filosofia da arte, i.e., a apresentação fenomenológica e filosófica da essência ou do valor "arte" e, do outro, a estética, i.e., a apresentação sistemática e normativa do que deve ser considerado como belo. Ou entre a filosofia moral (que pergunta o que é moralidade), e a ética normativa (que pergunta o que é moral). (TILLICH, 1990, p. 32).

No conceito de Tillich, aí está a diferença entre a filosofia da religião e a teologia. No campo dos estudos da religião, a filosofia da religião é a ciência que buscará as categorias universais acerca do saber religioso, enquanto que a teologia é a ciência que terá como tarefa a normatização e a sistematização do campo religioso, a partir de suas manifestações concretas, históricas. $\mathrm{O}$ autor define a teologia como uma parte da ciência da religião. Ela é sua parte concreta, sistemática e normativa, que usará das categorias desta para "ancorar o ponto de vista individual no ponto de vista confessional, no da história geral das religiões e na história geral do espírito" (TILLICH, 1990, p. 32).

Ao fixar a teologia como ciência normativa de algo concreto, Tillich declara negar duas hermenêuticas teológicas. Primeiro: "a Teologia não é a ciência de um objeto particular, situado ao lado de outros, que nós chamamos Deus." (TILLICH, 1990, p. 32). Segundo:

a teologia não é a apresentação científica de um conjunto revelado específico. Esta concepção supõe que façamos da revelação uma concepção supranatural e autoritária, que o espaço de perspectivas aberto pela história das religiões e que a crítica lógica e religiosa ao supranaturalismo conceitual superou. (TILLICH, 1990, p. 32). 
A teologia não pode considerar Deus um objeto de estudo, como fazem as ciências experimentais com seus objetos. Por outro lado, a teologia não pode considerar que seu saber emana de uma ordem superior revelada e que, portanto, as afirmações teológicas não estão sujeitas à análise. A teologia tillichiana analisará as manifestações culturais da religião sempre a partir de um chão, de um ponto de vista.

Depois de traçar a tarefa da teologia, Tillich, então, parte para a relação da religião com a cultura. Neste ponto, o teólogo visa superar a divisão estanque existente entre "sagrado" e "profano". Ele sinaliza que, desde que as igrejas protestantes reconheceram a existência de uma cultura secular, não é possível que a teologia se ocupe somente do que é estritamente religioso, pois isso seria ignorar toda criação cultural gerada por pontos de vistas individuais e que geram toda uma cultura secular de uma comunidade. Relegar a teologia somente ao âmbito religioso é dizer que há uma ética, uma estética, uma sociologia, uma ciência que é estritamente teológica, enquanto que esses mesmos pontos existem separadamente num âmbito secular. Por isso, Tillich defende que a teologia tem todo direito de apresentar sua normativa ética, mas ela já não pode mais ser elaborada isoladamente, e nem ser necessariamente superior, às outras normativas criadas na cultura secular. Em nível de proposição, uma ética teológica estará ao lado de uma ética alemã, burguesa ou ariana. Todas elas estarão propondo normativas éticas a partir de seus pontos de vista. Sendo assim, a ética teológica não será mais quem dita a regra do jogo, mas quem analisa a cultura a partir de um olhar teológico. A partir dessa afirmação, Tillich propõe que a ética teológica seja, então, uma teologia da cultura. (TILLICH, 1990, pp. 33-34)

Então, minha tese é a seguinte: isto que a ética teológica se propõe a fazer, somente uma teologia da cultura pode realizar, na medida em que ela não está relacionada somente à ética, mas também a todas as funções da cultura. Ela não é uma ética teológica, mas uma teologia da cultura. Daí a necessidade de algumas observações sobre a relação entre a cultura e a religião. A religião tem a particularidade de não estar relacionada a uma função psíquica particular. (TILLICH, 1990, p. 34). 
O conceito que Tillich tem de "religião" é primordial para se entender sua teologia da cultura. Religião para tillich não é uma manifestação cultural específica expressa através de um conjunto de ideias, doutrinas, grupo, ou instituição. Sob o olhar tillichiano, a religião não se enquadra em uma função cultural específica teórica e tampouco prática. Ela é uma potencialidade qualificadora da consciência humana que não está necessariamente ligada ao ato religioso, mas é a dimensão de autoconsciência que é seu fundamento e ao mesmo tempo seu abismo. Usando uma expressão que ele só empregará em um momento futuro, a religião é a dimensão da profundidade ${ }^{8}$ de todas as funções do espírito humano e, consequentemente, de todas as funções culturais que este possa criar. Portanto, a religião, objeto de estudo da teologia, não é achada somente nas manifestações culturais explicitamente religiosas, mas em qualquer função cultural na qual esta dimensão de profundidade esteja presente (na moral, na política, na ciência, na economia, na arte). A potencialidade religiosa, por sua vez, só pode existir a partir de uma função cultural. Tillich diz:

A conjunção do princípio religioso e da função cultural pode agora ocasionar a constituição de uma esfera religiosa específica compreendendo: um modo de conhecimento religioso (mito ou dogma), um domínio da estética religiosa (culto), uma formação religiosa da pessoa (santificação), uma forma de sociedade religiosa (a Igreja, com seu direito eclesial e sua ética comunitária particular). Em tais formas, a religião é atualizada, e somente a conjunção com as funções da cultura extra religiosa dão ao princípio religioso a capacidade de existir. (TILLICH, 1990, p. 35).

Tillich também aponta que por muito tempo a esfera religiosa requereu para si a qualidade de esfera na qual a religião era particularmente exprimida, mantendo uma relação de heteronomia com as outras esferas. Essa é a base dos conflitos que tomaram (e ainda tomam) a modernidade. Conflitos entre igreja e estado, comunidade religiosa e sociedade civil, arte e culto, ciência e dogma. E essa luta não cessará enquanto as esferas religiosas não respeitarem as esferas culturais em sua plena autonomia. Enquanto a esfera religiosa suprimir a autono-

8 Este termo é da tradução que a edição brasileira aqui usada faz de um dos textos de Tillich que compõem o livro "Theology of Culture", publicado em 1959. 
mia das outras esferas culturais, requerendo para si a exclusividade da experiência religiosa, haverá conflito. O autor vê, no conceito de religião que expõe, a solução para garantir a autonomia das esferas culturais. Ele diz:

A religião é a experiência do incondicionado, isto é, a experiência da realidade absoluta sobre a base da experiência do nada absoluto. Esta é a experiência do nada do que existe, do nada dos valores, do nada da vida pessoal. Lá onde esta experiência levou a um não absoluto, radical, ela se transforma subitamente em uma experiência também absoluta de realidade, em um sim radical. Não se trata de uma realidade nova, ao lado ou acima doas coisas: isto seria somente uma coisa de ordem superior que ainda cairia em um não. Mas através das coisas esta realidade se impõe a nós, esta que é ao mesmo tempo o não e o sim às coisas. Não é um ser, não é a substância, não é a totalidade do que é. É, para usar uma fórmula mística, o para-além-do-ser (Überseiende), que é ao mesmo o nada absoluto e algo absoluto. (TILLICH, 1990, p. 36).

Trazendo novamente um termo que será usado por Tillich posteriormente, a religião é a preocupação última ${ }^{9}$ do ser humano quando este é posto diante do sim e do não absoluto da existência. Portanto, é algo constitutivo do espírito humano e não de uma esfera religiosa particular. Em outras palavras, na conferência de 1919, ele diz: "O religioso não constitui, na vida do espírito, um princípio ao lado de outros: o caráter absoluto de toda consciência religiosa aboliria limitações desse gênero. Ao contrário, o religioso se atualiza em todas as províncias do espírito" (TILLICH, 1990, p. 35). Está, então, superado o conflito entre a ciência e o dogma. A autonomia da ciência está garantida e toda a heteronomia da religião já não faz sentido. Contudo, agora, as duas esferas, gozando de autonomia e livres da heteronomia, estão livres para estar 'sob a 'teonomia' da experiência religiosa fundamental que é em si paradoxal.” (TILLICH, 1990, p. 36). E não somente a ciência, mas a ética, a arte, a filosofia, a sociologia, a política e todas as esferas culturais podem ser teônomas, pois são potencialmente esferas nas quais se dará a experiência religiosa fundamental. Desta forma, Tillich apre-

9 O termo preocupação última surge quando Tillich, já nos Estados Unidos, elabora sua Teologia Sistemática, publicada originalmente em 1953. 
senta o trinômio autonomia, heteronomia e teonomia, que continuará sendo muito importante para a construção de sua teologia da cultura.

Pois, agora que tal horizonte foi aberto, o que cabe, então ao teólogo da cultura fazer? Se todas as funções culturais podem ser alvo de seu estudo, o que o diferenciará dos outros cientistas da cultura? Para responder estas questões, Tillich ruma para o fundamento do que seria, afinal, uma teologia da cultura. Neste fundamento está outro trinômio que também será muito importante para sua teologia a partir de então: Forma (Form), Conteúdo objetivo (Inhalt) e Conteúdo substancial (Gehalt).

A forma é onde está fundamentada a autonomia da função cultural. Por exemplo, uma arte tem a sua forma na própria autonomia de ser arte. Assim também a ética, o estado, etc. Essas são as formas nas quais as funções culturais são "classificadas". O conteúdo substancial (Gehalt) é onde está fundamentada a teonomia das funções culturais, ou seja, onde a experiência religiosa pode ser percebida. Já o conteúdo objetivo (Inhalt) é a realidade objetiva como a experimentamos em nossa existência no mundo. Ou seja, o objeto através do qual forma e conteúdo substancial se tornam fisicamente presentes. Como bem resume Tillich: "Podemos dizer então: o conteúdo (Gehalt), por meio da forma (Form), é capturado e trazido à expressão em um objeto (Inhalt). $\mathrm{O}$ objeto é o acidental, o conteúdo é o essencial e a forma é a mediação." (TILLICH, 1990, p. 38).

Para a teologia da cultura, interessa a relação entre forma e conteúdo substancial. Assim como a religião não pode existir sem uma esfera cultural concreta, o conteúdo substancial também não pode existir sem uma forma. Para que o primeiro seja percebido, tem que estar dentro do segundo. Contudo, uma manifestação cultural pode enfatizar uma ou outra dimensão. A partir disso, Tilllich diz:

Podemos formular a seguinte lei: quanto mais a forma for predominante, maior será a autonomia; quanto mais prevalecer o conteúdo, mais a cultura será teônoma. Mas uma não pode existir sem a outra; uma forma que não forma nada é tão inconcebível quanto um conteúdo que não se encaixa em uma forma. (TILLICH, 1990, p. 37). 
Tillich chega a usar a imagem de uma linha na qual numa extremidade se encontra o conteúdo puro e, em outra, a forma pura. Ambos formam uma unidade. Todavia, o conteúdo é preponderante à forma. A forma sempre será insuficiente face ao conteúdo que transborda sobre ela, irrompendo nela. A partir desta distinção, Tillich define a tarefa de uma teologia da cultura como uma que deve observar as manifestações culturais sempre do ponto de vista do conteúdo substancial (Gehalt), e não da forma. É no conteúdo que se encontram as experiências religiosas. Ele diz:

A tarefa de uma teologia da cultura é de perseguir e de exprimir este processo em todos os domínios e todas as criações da cultura. Contudo, não do ponto de vista da forma - isto seria a tarefa da ciência da cultura em questão - mas do ponto de vista do conteúdo, como teologia da cultura e não como sistemática da cultura. Importa que as experiências religiosas concretas, que se encontram ancoradas em todas as grandes manifestações da cultura, sejam salientadas e trazidas à expressão. (TILLICH, 1990, p. 37).

Compete à teologia da cultura lidar com o que é essencial, substancial, nas manifestações culturais analisadas por ela. O teólogo da cultura é um crítico da mesma. Buscando nela sempre a manifestação de sua dimensão de profundidade, ou seja, sua dimensão religiosa.

É através dessa base teórica que Tillich constrói sua teologia da cultura, através da qual ele julga ser capaz de criticar todas as manifestações culturais. A partir dela, Tillich escreveu textos críticos sobre sistemas políticos, filosofias, a conjuntura de sua época, artes plásticas e até dança. Como já foi dito, conforme o passar dos anos, muitos outros conceitos e aplicações foram encorpando sua teologia da cultura, tornando-a uma oportuna base teórica para análise crítica das várias funções culturais.

\subsection{Possibilidades de uma Teologia da Cultura de Consumo}

Não há uma relação direta entre o tema "cultura de consumo" e a "teologia da cultura" de Paul Tillich. Isso não é possível, pois o teólogo e filósofo morreu em 1965 e os estudos culturais acerca do consumo passaram a ganhar formalidade somente a partir da década de 80. Portanto, não encontraremos o termo "cultura de consumo" nos 
escritos tillichianos. Contudo, nosso autor sempre se dedicou a leituras perspicazes do tempo no qual vivia, fazendo algumas análises culturais, bem como leituras da conjuntura política e social de sua época. O que mais aproxima o pensamento do autor do nosso objeto material são suas frequentes críticas ao modelo econômico liberal, à sociedade industrial, à sociedade burguesa, ao capitalismo. $\mathrm{O}$ fato de Tillich ter sido um dos principais teóricos do movimento político-teológico chamado Socialismo Religioso da Alemanha contribuiu muito para que ele escrevesse sobre a relação entre política e sociedade no período entre o fim da Primeira Guerra e seu exílio nos Estados Unidos (1919-1933). A partir destas críticas e posicionamentos, é possível analisar a cultura de consumo a partir de alguns conceitos tillichianos.

Partindo dos conceitos apresentados na conferência de 1919 sugerimos a seguinte hipótese básica: A cultura de consumo é a absolutização da dimensão autônoma vendida como experiência teônoma. $\mathrm{Ou}$, em outras palavras, é a elevação das coisas cuja dimensão é meramente finita a uma dimensão de infinitude. Na cultura de consumo, os objetos de desejo são falsificados ao receberem, através do marketing, da propaganda, dos mediadores culturais, um conteúdo substancial (Gehalt) que não está originalmente neles. Estes não simbolizam o que poderiam simbolizar simplesmente por sua criação e finalidade, mas ganham significados muito maiores que os que conseguem suportar. Atribui-se às suas formas status de conteúdo substancial, usando as imagens e os poderes dos conteúdos objetivos (Inhalt) expostos nas embalagens e nos comerciais. A cultura de consumo não visa a profundidade das relações dos seres humanos com o mundo, mas sim o aprofundamento da superficialidade e da alienação existencial, vendendo-as como doadoras de sentido de vida.

Em 1926, Tillich escreve um livro intitulado "A situação religiosa dos tempos presentes". Em uma de suas seções, Tillich trata sobre a relação entre a economia e a sociedade. Para ele, a economia da sociedade burguesa é a representação de uma esfera cultural absolutamente autônoma. Ela é baseada somente na racionalização das ofertas e demandas visando um lucro infinito, sem considerar o todo orgânico que é a sociedade. Ele diz: 
A relação com as coisas na economia do livre mercado se torna dominadora, sem eros, sem caráter comunitário. As coisas se tornam mercadorias, ou seja, objetos cujo significado é produzir lucro pela compra e venda, mas não de expandir o círculo da vida pessoal. Elas são adquiridas e vendidas de maneira dominadora, sem relação de comunhão. Está aí porque não há limites para sua aquisição. A livre economia tende necessariamente para um imperialismo comercial que é infinito nele mesmo. Ele é infinito, mas face à finitude. Justamente por esta infinitude que lhe é própria, ela é a expressão mais perfeita da finitude autossuficiente, que nunca descansa, mas nunca supera a si mesma. (TILLICH, 1990, p. 199).

A pretensão do livre mercado é exatamente se fazer infinito, elevar-se como única via econômica possível. Este sistema econômico aliado à criação de uma cultura de consumo baseada na necessidade de escoamento da produção são componentes imprescindíveis para o sistema capitalista que tomou conta do mundo no século XX. Nele, não há espaço para relações afetivas, permanentes ou comunitárias, seja dos seres humanos entre si, seja entre estes e os objetos que o cercam. $\mathrm{Na}$ cultura de consumo, o problema não é a relação do ser humano com os objetos, isto sempre existiu, é um dado antropológico. O problema é a redução das coisas a um valor de mercado. Retira-se delas sua relacionalidade antropológica para dar-lhes significado mercadológico. É uma mudança de paradigma da relação do ser humano com o que o cerca. Tillich diz:

$\mathrm{Na}$ época pré-burguesa, a relação com as coisas comportava uma dimensão transcendente. A coisa, a propriedade, era o símbolo da participação na realidade dada por Deus (...). No entanto, a mercadoria é o símbolo da finitude infinita da pura vontade de dominação. Por consequência, as propriedades privadas como o campo, a casa, o gado, as mobílias, as vestimentas, etc., perderam seu caráter simbólico. Elas se tornaram mercadorias utilitárias, determinadas exclusivamente a fins de consumo, fabricadas, tratadas e dadas sem eros e sem consideração por sua individualidade. (TILLICH, 1990, p. 200).

Sem deixar de revelar o cunho romântico de seu pensamento, o que Tillich parece dizer é que, na era pré-burguesa, as coisas possuíam um simbolismo genuíno. Elas participavam da realidade humana por possuírem certo significado particular, participando da vida humana e de sua busca por sentido no mundo. Na cultura de consumo, este caráter 
simbólico genuíno se perdeu. No lugar dele, há o uso da dimensão simbólica para a produção do consumo, através da exploração horizontal da imaginação, do sonho e da fantasia que havia sido impulsionado pelo próprio Romantismo. Segundo Tillich, essa relação de perda do eros das coisas afeta, de forma particular, o âmbito religioso de duas formas: libertando os objetos de seu caráter sagrado; e elevando a pessoa humana acima da esfera das coisas. Esses seriam o efeito protestante da economia liberal, o esvaziamento do caráter erótico/sagrado das coisas Contudo, esse esvaziamento não significa libertação, mas sim uma escravização na qual a pessoa fica dominada e a serviço do vazio das coisas finitas. E isso faz com que própria pessoa se torne vazia e consagrada ao finito. Essa é a presença do espírito burguês na economia liberal. (TILLICH, 1990, p. 200).

O que Tillich percebeu em 1926 está na base da cultura de consumo de hoje. Dar ao que é finito caráter de infinitude. Essa atitude está também envolvida no conceito de demônico desenvolvido por Tillich neste mesmo ano. O demônico é exatamente o nome usado para caracterizar as esferas culturais que são finitas, não são destrutivas por natureza, mas que passam a requerer para si status de infinitude, e a partir dessa atitude passam a ter caráter destrutivo. É o caso da economia liberal, assim como também é o caso da cultura de consumo. Nem economia nem consumo são em si destrutivos, mas passam a ser quando reivindicam para si status de transcendência. Numa cultura de consumo, não são os objetos de produção em si que carregam uma significação maior do que eles mesmos, mas sim a esfera cultural que os envolve de um significado superlativizado. Portanto, essa esfera cultural tem caráter demônico. ${ }^{10}$

Por fim, o mesmo exercício pode ser feito com o conceito tillichiano já mais tardio de preocupação última (Ultimate Concern), que ele desenvolverá somente nos seus anos nos Estados Unidos. Para Tillich, preocupação última, é aquilo que nos toca incondicionalmente, que nos faz buscar a dimensão mais profunda das experiências humanas, ou seja, é o próprio conceito tillichiano de religião. Ele diz: "A religião, no sentido básico e mais abrangente da palavra, é 'preocupação

10 Sobre o caráter demônico do capitalismo ver (KELM, 2014, pp 51-70). 
suprema' [ultimate concern], manifesta em todas as funções criativas do espírito." (TILLICH, 2009, p. 44). Isto quer dizer que é possível considerar o capitalismo como uma falsa religião, pois, neste sistema, é necessário que todo objeto e toda experiência de consumo ganhe caráter de preocupação última e, segundo Tillich, "tudo aquilo que preocupa o ser humano de forma última se torna deus para ele." (TILLICH, 2015, p. 219). Contudo, o esforço para revestir a experiência de consumo de ultimacidade não é nada mais do que necessidade de fazer escoar a produção para que, assim, o sistema continue a operar.

\section{Conclusão}

Nosso objetivo aqui não foi construir uma teologia da cultura de consumo, mas sim, pensar sua possibilidade e apontar caminhos possíveis para sua construção. A cultura de consumo é um quadro cultural complexo no qual estão envolvidos aspectos econômicos, sociais, filosóficos, políticos e mesmo ecológicos. Este trabalho não daria conta de abarcar todos eles. O mesmo se pode afirmar sobre a teologia da cultura de Paul Tillich. Devido sua amplitude e complexidade, não seria possível abordar aqui todas as suas nuances e conceitos.

Há muitos outros conceitos tillichianos que poderiam servir como aparato teórico para se pensar a cultura de consumo e que, de alguma forma, seriam desdobramentos das pequenas tentativas apresentadas acima. O conceito de kairós como o tempo infinito dentro do finito poderia auxiliar numa reflexão acerca das experiências de consumo no mundo do entretenimento ou mesmo no ato de possuir. É possível que o conceito de incondicional, que é a descrição da autoconsciência humana como fundamento e abismo, possa conduzir a uma reflexão acerca de como o consumo e a posse podem levar a uma sensação de realidade plena, mascarando (sempre temporariamente) a ameaça do nada absoluto. Mesmo nunca se debruçando explicitamente sobre uma cultura de consumo, a teologia da cultura de Tillich parece trazer não poucos ferramentais teóricos possíveis para a análise da mesma. O desafio, na verdade, está em perceber os mais apropriados. 


\section{Referências bibliográficas}

ADORNO, T.; HORKHEIMER, M. Dialética do esclarecimento. Rio de Janeiro: Jorge Zahar, 1985.

ALVES, Rubem. O que é religião? São Paulo: Edições Loyola, 1999.

. Variações sobre a vida e a morte: ou o feitiço erótico-herético da teologia. São Paulo: Loyola, 2009.

ARNOULD, E. J.; THOMPSON, C. J. Consumer culture theory (CCT): twenty years of research, Journal of Consumer Research, v. 31, n. 4, 2005, pp. 868-882.

BAUDRILlARD, J. A sociedade de consumo. São Paulo: Edições 70, 1981. . O sistema dos objetos. São Paulo: Perspectiva, 2008.

. Simulacros e simulações. Lisboa: Relógio D’água, 1981.

BINGEMER, M. O mistério e o mundo. Rio de Janeiro: Rocco, 2013.

CALVANI, C. E. Teologia da arte. São Paulo: Fonte Editorial; Paulinas, 2010. CAMPBELL, C. A ética romântica e o espírito do capitalismo moderno. Rio de Janeiro: Rocco, 2001.

DOUGLAS, M.; ISHERWOOD, B. O mundo dos bens: para uma antropologia do consumo. Rio de Janeiro: UFRJ, 2006.

FEATHERSTONE, M. Cultura de consumo e pós-modernismo. São Paulo: Studio Nobel, 1995.

FONTENELLE, I. Cultura de consumo: Fundamentos e formas contemporâneas. Rio de Janeiro: FGV, 2017.

GIBELlini, R. A teologia do século XX. São Paulo: Loyola, 1998.

HIGUET, E. (org.). Teologia e modernidade. São Paulo: Fonte Editorial, 2005. KELM, T. R. O capitalismo como religião visto à luz do conceito de demônico de Paul Tillich. Correlatio 13, n. 26 (2014), pp 51-70.

LIMA, D. Consumo: uma perspectiva antropológica. Petrópolis: Vozes, 2010.

LIPOVETSKY. G.; SERROY, J. A estetização do mundo. São Paulo: Companhia das Letras, 2015.

McCRACKEN, G. Cultura e consumo: novas abordagens ao caráter simbólico dos bens e das atividades de consumo. Rio de Janeiro: Mauad, 2003.

McKENDRICK, N.; BREWER, J.; PLUMB, J. H. The Birth of a Consumer Society: The Commercialization of Eighteenth-Century England. Bloomington: Indiana Press University, 1982. 
MUELLER, E.; BEIMS, R. (Orgs.). Fronteiras e Interfaces: O pensamento de Paul Tillich em perspectiva interdisciplinar. São Leopoldo: Sinodal, 2005. PINTO, M.; BATINGA, G. (Orgs.). Cultura e consumo no Brasil: estado atual e novas perspectivas. Belo Horizonte: PUC Minas, 2018.

ROCHA, E.; FRID, M; CORBO, W. O paraíso do consumo: Émile Zola, a magia e os grandes magazines. Rio de Janeiro: Mauad X, 2016.

SENNETT, R. O declínio do homem público. São Paulo: Companhia das Letras, 1998.

TILLICH, P. La dimension religieuse de la culture: Écrits du premier enseignement. Vol. 1. RICHARD, J. (dir.). Quebec - Paris -Genève: Laval - Cerf - Labor et Fides, 1990.

. Teologia da Cultura. São Paulo: Fonte Editorial, 2009.

. Teologia Sistemática. São Leopoldo: Sinodal, 2014.

VEBLEN, T. A teoria da classe ociosa: um estudo econômico das instituições. São Paulo: Nova Cultural, 1988.

WILLIAMS, R. Dream worlds: mass consumption in late nineteenth century France. Berkeley: University of California Press, 1982.

ZOLA, E. O paraíso das damas. São Paulo: Estação liberdade, 2008. 